\title{
ProNGF, a cytokine induced after myocardial infarction in humans, targets pericytes to promote microvascular damage and activation
}

\author{
Chia-Jen Siao, ${ }^{1}$ Christina U. Lorentz, ${ }^{1}$ Pouneh Kermani, ${ }^{1}$ Tina Marinic, ${ }^{1}$ \\ John Carter, ${ }^{2}$ Kelly McGrath, ${ }^{1}$ Victoria A. Padow, ${ }^{1}$ Willie Mark, ${ }^{7}$ \\ Domenick J. Falcone, ${ }^{5}$ Leona Cohen-Gould, ${ }^{3,4}$ Diana C. Parrish, ${ }^{6}$ \\ Beth A. Habecker, ${ }^{6}$ Anders Nykjaer, ${ }^{8}$ Lora H. Ellenson, ${ }^{5}$ Lino Tessarollo, ${ }^{9}$ \\ and Barbara L. Hempstead ${ }^{1}$

\footnotetext{
'Division of Hematology/Medical Oncology and 2Division of Cardiovascular Pathophysiology, Department of Medicine, ${ }^{3}$ Department of Biochemistry, ${ }^{4}$ Department of Cell and Developmental Biology, and ${ }^{5}$ Department of Pathology, Weill Cornell Medical College, New York, NY 10065

${ }^{6}$ Department of Physiology and Pharmacology, Oregon Health and Science University, Portland, OR 97239

${ }^{7}$ Developmental Biology Program, Sloan-Kettering Institute, New York, NY 10065

${ }^{8}$ Department of Medical Biochemistry, University of Aarhus, Aarhus DK-8000, Denmark

${ }^{9}$ Mouse Cancer Genetics Program, Center for Cancer Research, National Cancer Institute, National Institutes of Health,
} \\ Bethesda, MD 21702
}

\author{
CORRESPONDENCE \\ B.L. Hempstead: \\ blhempst@med.cornell.edu \\ Abbreviations used: HA, \\ hemagglutinin; IB4, isolectin \\ B4; ICAM, intercellular adhe- \\ sion molecule; I-R, ischemia- \\ reperfusion; $\mathrm{MI}$, myocardial \\ infarction; NGF, nerve growth \\ factor; p75 ${ }^{\mathrm{NTR}}$, p75 neuro- \\ trophin receptor; PDGFR- $\beta$, \\ platelet-derived growth factor \\ receptor $\beta$; SorCS2, sortilin- \\ related VPS10 domain contain- \\ ing receptor 2 .
}

Treatment of acute cardiac ischemia focuses on reestablishment of blood flow in coronary arteries. However, impaired microvascular perfusion damages peri-infarct tissue, despite arterial patency. Identification of cytokines that induce microvascular dysfunction would provide new targets to limit microvascular damage. Pro-nerve growth factor (NGF), the precursor of NGF, is a well characterized cytokine in the brain induced by injury. ProNGF activates $\mathrm{p} 75$ neurotrophin receptor $\left(\mathrm{p} 75^{\mathrm{NTR}}\right)$ and sortilin receptors to mediate proapoptotic responses. We describe induction of proNGF by cardiomyocytes, and $\mathrm{p} 75^{\mathrm{NTR}}$ in human arterioles after fatal myocardial infarction, but not with unrelated pathologies. After mouse cardiac ischemia-reperfusion (I-R) injury, rapid up-regulation of proNGF by cardiomyocytes and $p 75^{\text {NTR }}$ by microvascular pericytes is observed. To identify proNGF actions, we generated a mouse expressing a mutant $\mathrm{Ng} f$ allele with impaired processing of proNGF to mature NGF. The proNGF-expressing mouse exhibits cardiac microvascular endothelial activation, a decrease in pericyte process length, and increased vascular permeability, leading to lethal cardiomyopathy in adulthood. Deletion of $\mathrm{p} 75^{\mathrm{NTR}}$ in proNGF-expressing mice rescues the phenotype, confirming the importance of $p 75^{\mathrm{NTR}}$-expressing pericytes in the development of microvascular injury. Furthermore, deficiency in p75 ${ }^{\text {NTR }}$ limits infarct size after I-R. These studies identify novel, nonneuronal actions for proNGF and suggest that proNGF represents a new target to limit microvascular dysfunction.

The primary therapeutic goal after acute myocardial infarction (MI) is to limit the duration of ischemia and to establish reperfusion using angioplasty or thrombolysis. However, even with improved arterial flow, a significant proportion of patients experience microvascular damage that leads to decreased microvascular perfusion and chronically impaired heart function (Eltzschig and Collard, 2004; Bekkers et al., 2010). At this

$\overline{\text { C.-J. Siao and C.U. Lorentz contributed equally to this paper. }}$ time, the proinflammatory cytokines induced by ischemia that mediate microvascular dysfunction or apoptosis after cardiac ischemia remain largely unknown.

We considered whether nerve growth factor (NGF), and specifically its uncleaved precursor

2012 Siao et al. This article is distributed under the terms of an AttributionNoncommercial-Share Alike-No Mirror Sites license for the first six months after Noncommercial-Share Alike-No Mirror Sites license for the first six months after
the publication date (see http://www.rupress.org/terms). After six months it is available under a Creative Commons License (Attribution-Noncommercial-Share Alike 3.0 Unported license, as described at http://creativecommons.org/licenses/ by-nc-sa/3.0/). 

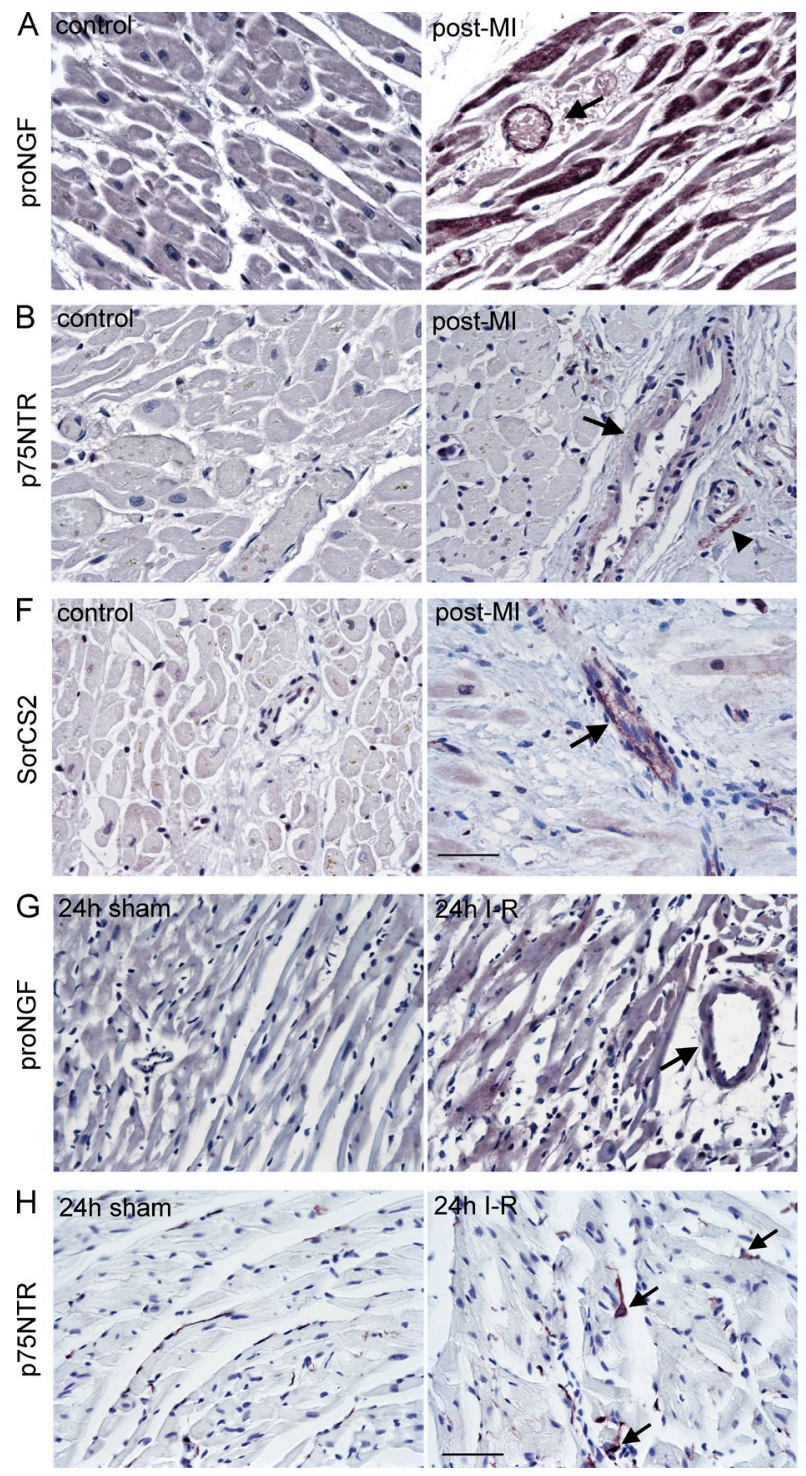
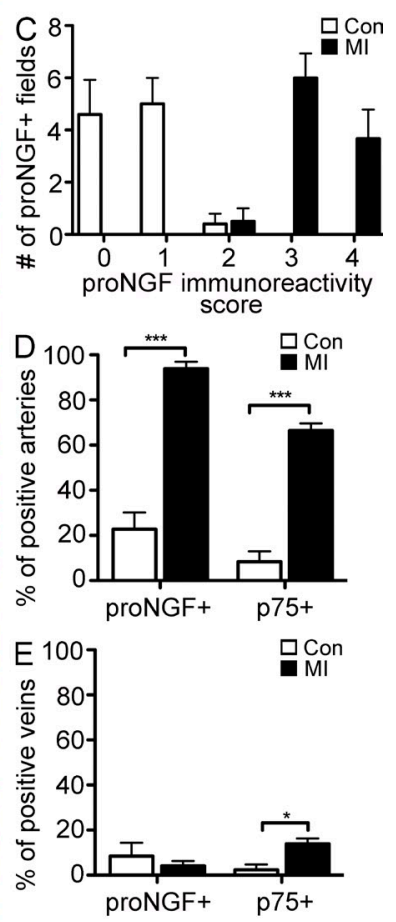

Figure 1. Expression of proNGF and its receptors $\mathrm{p} 75^{\mathrm{NTR}}$ and SorCS2 are coordinately up-regulated after myocardial ischemia in humans and mice. (A) Immunohistochemical detection of the prodomain of proNGF demonstrates increased proNGF reactivity in both cardiomyocytes and in vascular smooth muscle cells (arrow) in the periinfarct region of the hearts of patients that died from recent $\mathrm{MI}$ (post-MI, right) compared with patients that died of noncardiac related causes (control, right). (B) Immunohistochemical detection of $p 75^{\text {NTR }}$ demonstrates induction of p $75^{\text {NTR }}$ in mural cells of arterioles in post-MI patients (right, arrow) compared with noncardiac patients (control, left). Arrowhead indicates p75 ${ }^{\text {NTR }}$ positive nerve fiber. (C) Quantification of proNGF immunoreactivity in cardiac myocytes of noncardiac patients and from the peri-infarct region of post-MI patients. ProNGF immunoreactivity in cardiomyocytes was quantified using a semiquantitative method in which 10 fields of view were scored by a blinded individual. Each field of view was given a score of 0-4: 0 for absence of immunoreactivity, 1 for weak immunoreactivity, 2 for modest immunoreactivity, 3 for moderate immunoreactivity, and 4 for strong immunoreactivity. The scores from the fields of view were averaged. (D and E) Quantification of proNGF and p75 NTR immunoreactivity in the cardiac arteries (D) and veins (E) of the peri-infarct region of post-MI patients and noncardiac patients. The number of proNGF or p75 NTR positive vessels is presented as a percentage of total vessels counted. The scores were averaged and the error bars represent the SEM. ${ }^{*}, \mathrm{P}<0.05 ;{ }^{* *}, \mathrm{P}<0.001$. (F) Immunohistochemical detection of SorCS2 demonstrates induction of SorCS2 in the cardiac vasculature (arrow) of post-MI patients compared with noncardiac patients. (G) Immunohistochemical detection of the prodomain of proNGF demonstrates increased proNGF reactivity in the infarct and peri-infarct regions of the mouse heart after I-R surgery ( $24 \mathrm{~h} \mathrm{I-R}$, right, arrow indicates proNGF-positive vascular smooth muscle cells) compared with sham-operated animals ( $24 \mathrm{~h}$ sham, left). $(\mathrm{H})$ Immunohistochemical detection of p $75^{\mathrm{NTR}}$ in the mouse heart after I-R reveals induction of cell-associated $p 75^{\mathrm{NTR}}$ (right, arrows) compared with hearts from sham-operated mice in which p75 NTR is primarily detected in cardiac nerve fibers (left). (A-F) $n=6$ patients that died after myocardial ischemia, and five patients that died of noncardiac causes $(\mathrm{G}$ and $\mathrm{H}) n=3-4$ mice/group. Bars, $50 \mu \mathrm{m}$.

proNGF, could act as a potential proapoptotic and proinflammatory cytokine in the ischemic heart. NGF is initially synthesized as proNGF, which is normally cleaved intracellularly to release mature NGF (Heymach and Shooter, 1995). Mature NGF binds to the TrkA receptor tyrosine kinase to mediate survival and differentiative effects in neurons (Reichardt, 2006). Under pathological conditions, proNGF is secreted and acts as a distinct ligand to promote neuronal apoptosis by binding to the p75 neurotrophin receptor (p75 ${ }^{\mathrm{NTR}}$ ), a member of the tumor necrosis factor receptor family, and the transmembrane receptor sortilin (Lee et al., 2001; Nykjaer et al., 2004). This receptor complex activates stress and apoptotic signaling molecules, such as JNK (c-Jun N-terminal kinase) and caspase-3 (Nykjaer et al., 2005; Jansen et al., 2007; Volosin et al., 2008; Hempstead, 2009).

ProNGF and $\mathrm{p} 75^{\mathrm{NTR}}$ are present at low to undetectable levels in normal, uninjured adult tissues (Fanburg-Smith and Miettinen, 2001; Harrington et al., 2004; Lommatzsch et al., 2005; Hempstead, 2009). However, they are rapidly induced after acute neuronal injury and mediate cell death or degeneration after seizures or axotomy (Harrington et al., 2004; Volosin et al., 2008). In addition, proNGF is up-regulated in neurodegenerative diseases and aging (Pedraza et al., 2005; Jansen et al., 2007). However, ngf mRNA is expressed in many organs, and secreted mature NGF promotes sympathetic innervation during development and regulates sympathetic 
tone in the adult (Donovan et al., 1995; Glebova and Ginty, 2005; Habecker et al., 2008). In the adult heart, mature NGF is secreted tonically by cardiac myocytes to modulate synaptic transmission by sympathetic neurons (Luther and Birren, 2006). Additionally, within hours of cardiac ischemia-reperfusion (I-R) injury in rodents, ngf mRNA is induced (Hiltunen et al., 2001), and immunoreactivity to the mature NGF domain increases in human hearts after acute MI (Meloni et al., 2010). These studies, however, do not distinguish whether mature NGF or proNGF is induced after cardiac ischemia. P75 ${ }^{\text {NTR }}$ expression is also induced in the vasculature after acute injury to the aorta (Donovan et al., 1995), and p $75^{\text {NTR }}$ activation promotes vascular smooth muscle and endothelial cell death in vitro (Wang et al., 2000; Kim et al., 2004). Genetic deletion of $\mathrm{p} 75^{\mathrm{NTR}}$ in mice $\left(p 75^{-/-}\right)$results in reduced apoptosis of vascular smooth muscle cells after vascular injury, suggesting that locally produced neurotrophins regulate this response (Kraemer, 2002).

The induction of $n g f$ mRNA by cardiomyocytes and of $\mathrm{p} 75^{\mathrm{NTR}}$ by vascular cells after injury suggests a potential paracrine role for NGF or proNGF in modulating vascular integrity. Microvascular endothelial survival depends on reciprocal interactions with neighboring pericytes during development, and pericytes maintain microvascular structure and function in the adult animal (Gaengel et al., 2009). Disruption of endothelial cell-pericyte communication during development leads to vascular hemorrhage and embryonic death, as is readily observed in platelet-derived growth factor $B(P d g f b)$ - or platelet-derived growth factor receptor $\beta$ (Pdgfrb)-deficient mice, where pericyte recruitment to specific vascular beds is impaired (Lindahl et al., 1997; Hellström et al., 1999; Bjarnegård et al., 2004). In adult mice, TGF- $\beta$ and bone morphogenetic proteins play critical roles in maintaining pericyte survival and promoting microvascular integrity (El-Bizri et al., 2008; Walshe et al., 2009). These observations suggest that disruption of endothelial cell-pericyte interactions during cardiac microvascular maturation may lead to cardiac dysfunction later in life.

In this study, we examined the expression of proNGF and its receptors, $\mathrm{p} 75^{\mathrm{NTR}}$ and sortilin-related VPS10 domain containing receptor 2 (SorCS2), a sortilin family member (Willnow et al., 2008), in the infarcted myocardium after cardiac ischemia in human autopsy material and in an established mouse model of I-R injury. We observed the induction of proNGF by cardiac myocytes and arterioles, and of $\mathrm{p} 75^{\mathrm{NTR}}$ and SorCS 2 by mural cells of arterioles in the peri-infarct region of individuals who died after a recent MI. Comparable induction patterns were observed in mouse tissue after I-R injury. To investigate the consequences of proNGF expression on the cardiac vasculature, we generated and analyzed a knockin mouse that expresses one allele of cleavage-resistant proNGF (proNgfhemagglutinin $[H A] /^{+}$). We found that proNGF overexpression targets $\mathrm{p} 75^{\mathrm{NTR}}$ - and SorCS2-immunoreactive pericytes in the perinatal period, leading to a reduction of pericyte processes, microvascular endothelial activation, and increased vascular permeability in young adulthood, culminating in a dilated cardiomyopathy and premature lethality. This phenotype is

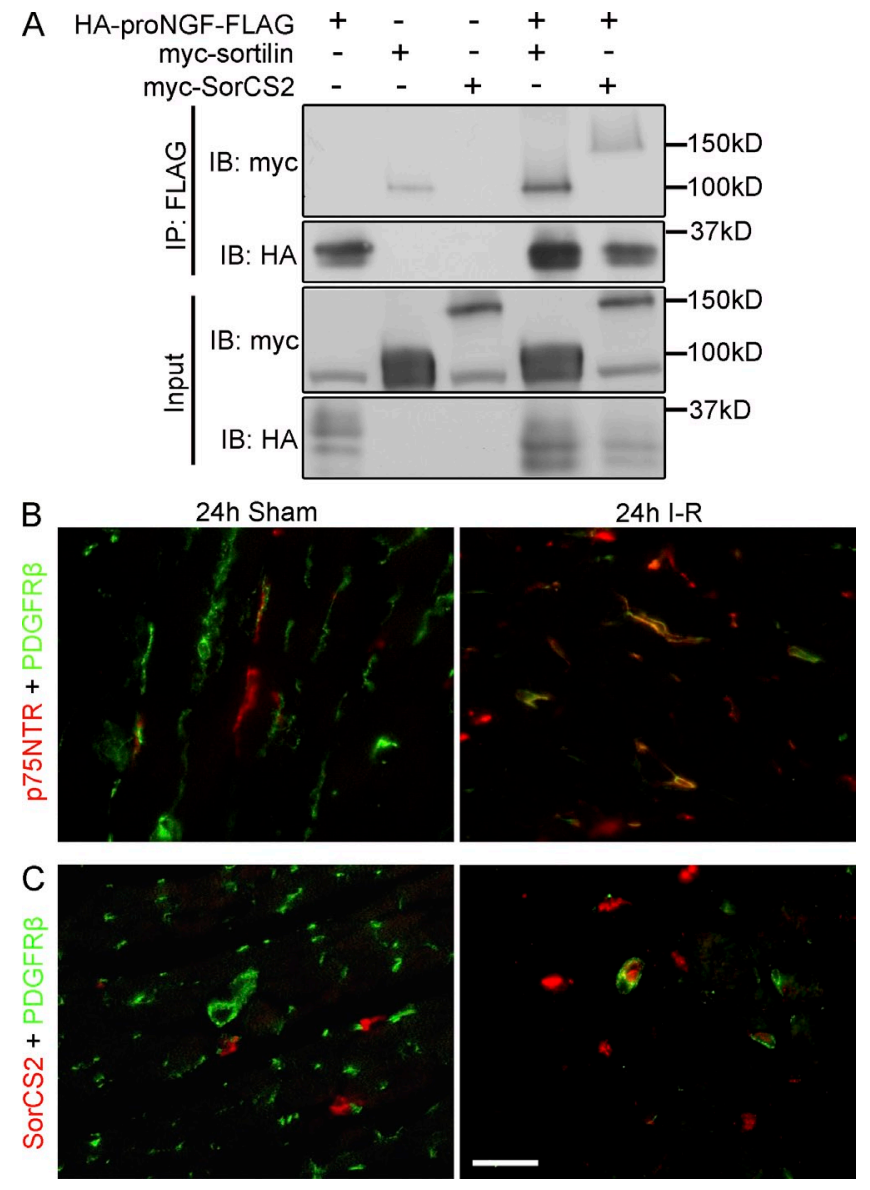

Figure 2. $\quad \mathrm{p} 75^{\mathrm{NTR}}$ and SorCS2, to which proNGF also binds, are up-regulated in PDGFR- $\boldsymbol{\beta}^{+}$pericytes after I-R in mice. (A) Immunoprecipitation-Western blot analysis from 293T cells transfected with the indicated plasmids. The experiment was performed three independent times. (B) p75 NTR (red) expression on PDGFR- $\beta^{+}$(green) pericytes in the peri-infarct regions of injured hearts compared with pericytes of uninjured myocardium. (C) SorCS2 (red) expression in a population of pericytes coexpressing PDGFR- $\beta$ (green) in the injured myocardium after I-R. (B and C) Bar, $25 \mu \mathrm{m} . n=3$ mice/group.

rescued in mice that are deficient in $\mathrm{p} 75^{\mathrm{NTR}}$. Furthermore, deficiency in $\mathrm{p} 75^{\mathrm{NTR}}$ limits the infarct size expansion after myocardial I-R injury, when compared with infarct size in wild-type mice. These observations identify proNGF and $\mathrm{p} 75^{\mathrm{NTR}}$ as potential therapeutic targets to limit microvascular dysfunction in the ischemic heart.

\section{RESULTS}

Myocardial ischemia induces expression of proNGF and its receptors in the human and mouse heart

To determine whether proNGF induction is observed in extraneural organs after ischemic injury, we examined proNGF immunoreactivity in human heart tissue from patients that succumbed to a fatal MI as compared with heart tissue from individuals that died of nonatherosclerotic causes. Using antisera specific to the prodomain of proNGF that detects proNGF but not mature NGF (Harrington et al., 2004), we 


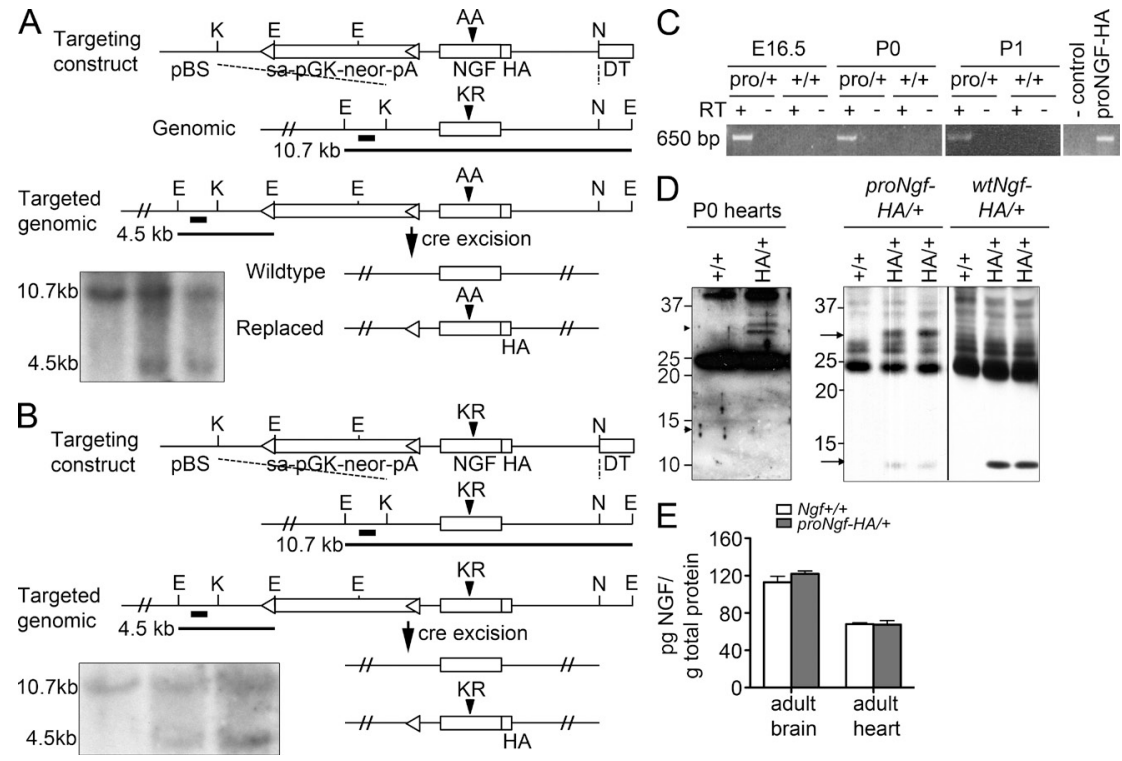

Figure 3. Generation and characterization of the proNgf-HA/+ and wtNgf-HA/+ knock-in mice. (A) Schematic of $n g f$ gene targeting with the prongf-HA allele. The dark bars indicate Southern blot probe sequence and expected product sizes. Inset, Southern blot analysis of genomic DNA. (B) Schematic of wild-type ngf-HA gene targeting. Inset, Southern blot analysis of genomic DNA. (C) RT-PCR analysis to detect proNGF-HA mRNA from embryonic day 16.5, postnatal day 0 , and postnatal day 1 mouse hearts. Control, pcDNA vector. proNGF-HA, pcDNA-proNGF-HA plasmid positive control. The experiments were repeated two independent times. (D) ImmunoprecipitationWestern blot analysis of proNGF or NGF expression. Left, representative lysates of PO $\mathrm{Ngfl}^{++}$and proNgf-HA/+ hearts (three hearts pooled for each lane) analyzed for proNGF-HA ( $\sim 32 \mathrm{kD})$ and mature NGF-HA $(\sim 13 \mathrm{kD})$ in proNgf-HA/+ and $\mathrm{Ngff}^{+/}$ hearts, experiment performed two independent times. Right, similar analysis performed in adult brain lysates. Experiment was performed four independent times. The black line indicates that intervening lanes were spliced out. (E) ELISA for total levels of NGF protein isoforms in the brain and in the heart of $\mathrm{Ngft/+}$ versus proNgf-HA/++ mice $(n=3$ mice/ group, mean $\pm S D$ ). observed increased proNGF immunoreactivity in cardiac myocytes in the peri-infarct region (Fig. 1, A [right] and C) but not in remote areas in hearts from patients with recent MI (not depicted). Little to no proNGF immunoreactivity was detected in the hearts of patients that died of noncardiac causes (Fig. 1, A [left] and C). Anti-proNGF immunoreactivity was also observed in the smooth muscle layer of most arterioles in the peri-infarct region from patients that had experienced a fatal MI but not in heart sections from noncardiac patients (Fig. 1, A [arrow] and D). ProNGF immunoreactivity was not observed in the mural wall of veins or venules (Fig. 1 E). We next examined the expression of $\mathrm{p} 75^{\mathrm{NTR}}$. In the heart tissue of noncardiac patients, $\mathrm{p} 75^{\text {NTR }}$ immunoreactivity was not detected (Fig. $1 \mathrm{~B}$, left) except in nerve fibers in the adventitia of arteries (Fig. $1 \mathrm{~B}$ and not depicted). However, in the peri-infarct region of patients with recent MI, immunoreactivity was observed in mural cells of arterioles, but in few veins (Fig. 1, B [right, arrow], D, and E). Lastly, we examined the expression of SorCS2, a sortilin family member (Willnow et al., 2008). Increased SorCS2 immunoreactivity was observed in arterioles within the peri-infarct region of patients with recent $\mathrm{MI}$ but was not detected in the vasculature of noncardiac patients (Fig. $1 \mathrm{~F}$ ).

To investigate the expression of proNGF and $\mathrm{p} 75^{\mathrm{NTR}}$ in a rodent $\mathrm{I}-\mathrm{R}$ model that recapitulates many features of severe myocardial ischemia in humans, transient ischemia was induced in C57BL6/J mice by occlusion of the left anterior descending coronary artery, followed by reperfusion for $24 \mathrm{~h}$ or $3 \mathrm{~d}$. Using this model, we found that proNGF immunoreactivity was up-regulated in cardiac myocytes in the infarct and peri-infarct regions of the injured myocardium after $24 \mathrm{~h}$ of reperfusion, whereas low levels of proNGF was detected in the hearts of sham-operated mice (Fig. 1 G). ProNGF immunoreactivity remained elevated in the peri-infarct myocardium after $3 \mathrm{~d}$ of reperfusion (unpublished data).

We next examined the expression of proNGF receptors, including p $75^{\mathrm{NTR}}$, sortilin (Nykjaer et al., 2004), and SorCS2 in the mouse heart after I-R. Although $\mathrm{p} 75^{\mathrm{NTR}}$ is expressed by cardiac sympathetic fibers in both uninjured and injured myocardium (not depicted), cell-associated $\mathrm{p} 75^{\mathrm{NTR}}$ expression was increased (Fig. $1 \mathrm{H}$ ) and colocalized with PDGFR- $\beta^{+}$ pericytes (Fig. 2 B, right) but not isolectin $\mathrm{B} 4(\mathrm{IB} 4)^{+}$endothelial cells (not depicted) in the peri-infarct region after $24 \mathrm{~h}$ of reperfusion. Induction of $\mathrm{p} 75^{\mathrm{NTR}}$ was observed in the microvasculature but not in coronary arteries or veins. P75 $5^{\text {NTR }}$ immunoreactivity was rarely detected in the vasculature from the uninjured cardiac tissue from sham-operated animals (Fig. 2 B, left). We also evaluated the expression of sortilin and SorCS2, to which proNGF also binds (Fig. 2 A). SorCS2 (Fig. 2 C), but not sortilin (not depicted), was up-regulated in the infarcted heart, specifically in PDGFR- $\beta$-expressing pericytes. The coordinate induction of proNGF in cardiac myocytes, and of $\mathrm{p} 75^{\mathrm{NTR}}$ and SorCS2 in pericytes after injury, led us to hypothesize that proNGF may act in a paracrine manner to modulate microvascular function.

\section{In vivo effects of increased expression of proNGF}

To directly evaluate the action of proNGF in the heart, we generated a mouse in which the ngf coding exon was replaced with a mutant allele with impaired furin cleavage (Lee et al., 2001) 
using gene targeting. This mutant ngf allele contains a C-terminal HA tag to facilitate detection (proNgf- $\mathrm{HA}^{+}$; Fig. 3 A). As a control, mice were also generated in which one endogenous $n g f$ coding exon was replaced with a wild-type mouse $n g f$ sequence with a C-terminal HA tag $\left(w t \mathrm{~N} g f-\mathrm{HA} /^{+}\right.$; Fig. $3 \mathrm{~B}$ ). The HA-epitope tag facilitates detection of proNGF or mature NGF proteins in these mice, as total NGF levels in normal tissues are at subnanomolar concentrations (Yang et al., 2009). ProNgf-HA/ $/^{+}$mice express one allele of proNgf-HA and one endogenous $n g f$ allele to maintain viability. $\mathrm{Ng}^{+/-}$ mice (Crowley et al., 1994) were analyzed in parallel for phenotype comparison and to permit detection of potential gainof-function phenotypes of proNGF.

ProNgf-HA $/^{+}$mice expressed proNGF mRNA in the heart (Fig. $3 \mathrm{C}$ ), and the level of total NGF proteins was comparable to that of wild-type littermates, as measured by an ELISA that detects both proNGF and mature NGF (Fig. 3 E). Western blot analysis of tissue lysates confirmed that pro $\mathrm{Ngf-HA} /^{+}$mice express predominantly proNGF-HA $(32 \mathrm{kD}$ protein) from the proNGF-HA allele, whereas $w t \mathrm{Ngf-HA} /{ }^{+}$mice express predominantly mature NGF (13 kD protein) from the $w t \mathrm{Ngf-HA}{ }^{+}$ allele (Fig. $3 \mathrm{D}$, right). ProNGF (32 kD) was detected in the lysates of hearts of pro $\mathrm{Ng}-\mathrm{HA} /^{+}$but not wild-type control mice (Fig. $3 \mathrm{D}$, left). These results indicate that the cleavage of proNGF to mature NGF was impaired in $\operatorname{proNgf-HA} /{ }^{+}$mice, resulting in increased expression of the proNGF isoform.

In the hearts of 8-mo-old proNgf-HA/ ${ }^{+}$mice, we observed marked structural and histological changes when compared with age-matched wild-type $\left(\mathrm{N} g f^{+/+}\right)$littermates (Fig. 4, A, B, $\mathrm{D}$, and E), as well as with $\mathrm{Ng} f^{+-}$and $w t \mathrm{Ngf-HA} /^{+}$mice (not depicted). ProNgf-HA/ ${ }^{+}$mice exhibit biventricular enlargement with myocardial wall thinning (Fig. 4, A and B), extensive myocardial fibrosis (Fig. 4, D, E, G, H, and J), and increased numbers of infiltrating CD68-expressing histiocytes (not depicted) as compared with the myocardium of control mice. However, no evidence of myocyte cell death was observed in the proNgf- $\mathrm{HA} /{ }^{+}$mice at early ages (4 wk of age) or at later ages ( 8 mo old) as measured by cleaved caspase- 3 immunofluorescence (unpublished data). In addition, matrix metalloproteinase-2 and -9 activity was unchanged in the proNgf-HA/ ${ }^{+}$mice (unpublished data). Quantitation of collagen deposition as detected by Masson's trichrome within the hearts of pro $\mathrm{Ngf-HA} /{ }^{+}$mice and wild-type littermates documented increased levels in proNgf-HA $/^{+}$animals of 6-8 mo of age $\left(5.77 \%\right.$ pro $\mathrm{Ngf}-\mathrm{HA}^{/^{+}}$vs. $0.39 \% \mathrm{Ngf}^{+/+}, n=4$ of each genotype; Fig. 4, G, H, and J). These phenotypic changes are reminiscent of the pathology observed in patients with dilated cardiomyopathy (Roura and Bayes-Genis, 2009).

To evaluate ultrastructural changes in the myocardium that result from increased proNGF expression, we examined left ventricular subendocardial heart sections from pro $\mathrm{Ng} f-\mathrm{HA}^{+}$, wild-type $\left(\mathrm{Ng}^{+/+}\right)$, and heterozygous $\left(\mathrm{Ngf}^{+/-}\right)$mice of 4 mo of age by transmission electron microscopy (Fig. 5, A-C). Although the hearts from $\mathrm{Ng} f^{+/+}$and $\mathrm{Ng}^{+/-}$mice appeared normal, the myocardium from proNgf-HA/ ${ }^{+}$mice was notable for focal myofibrillar damage and focal collagen deposition
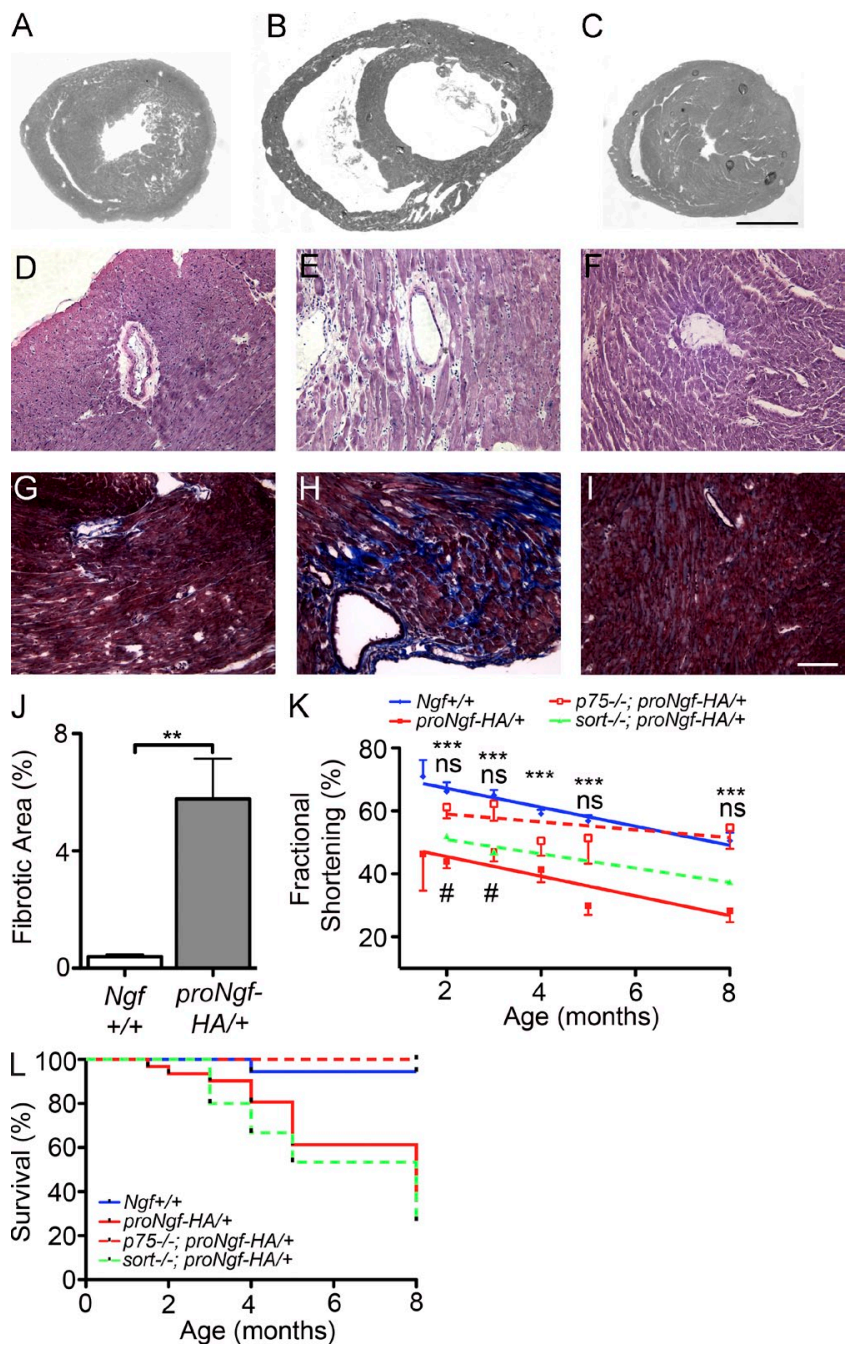

Figure 4. Adult proNgf-HA/ ${ }^{+}$mice exhibit dilated cardiomyopathy, fibrosis, and contractile dysfunction. (A-C) H\&E-stained sections of

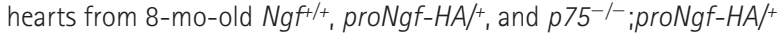
mice. (D-F) Higher magnification images. (G-I) Masson's trichrome analysis of hearts from 8-mo-old $\mathrm{Ngf+/}$, proNgf-HA/+, and $p 7^{-/-}$; proNgf$H A /^{+}$mice. Red, myocardium. Black, nuclei. Blue, collagen matrix.

(J) Quantification of cardiac fibrosis in 6-8-mo-old proNgf-HA/+ mice and $\mathrm{Ngfl}^{+/+}$littermate mice. Three to four fields of view from the subendocardium were analyzed for each animal and was averaged. Mean \pm SEM, $n=4 /$ genotype. (K) Fractional shortening in proNgf-HA/+ mice (solid red squares) compared with $\mathrm{Ngffl+}^{+/}$(blue diamonds), $\mathrm{p}^{-/-}$: $\mathrm{proNgf-HA} /^{+}$ (open red squares), and sort ${ }^{-/-}$:proNgf-HA/+ mice (filled green triangles). ${ }^{* * *}, \mathrm{P}<0.005$ proNgf-HA/+ compared with $\mathrm{Ngft}^{+{ }^{+}} ; \#, \mathrm{P}<0.05$ sort $^{-/-}$: proNgf-HA/+ compared with $\mathrm{Ngft/+}^{+}$, Student's $t$ test. Solid blue and red, and dashed red and green lines, linear regression curve for each genotype. (L) Kaplan-Meier graph of survival of $\mathrm{Ngft/+}^{+/}$(solid blue line), proNgf-HA/+

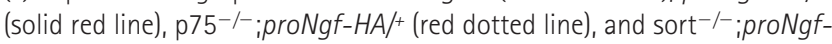
$H A /+$ (green dotted line) mice. Bars: (A-C) 2 mm; (D-I) $100 \mu \mathrm{m}$.

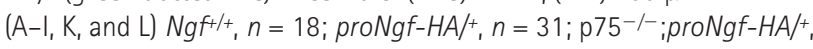
$n=14 ;$ sort $^{-/} ;$proNgf-HA/ $^{+}, n=15$.

(unpublished data). In addition, many endothelial cells exhibited attenuation of the cytoplasm with occasional overt rupture and extravasation of erythrocytes from the vascular lumen 

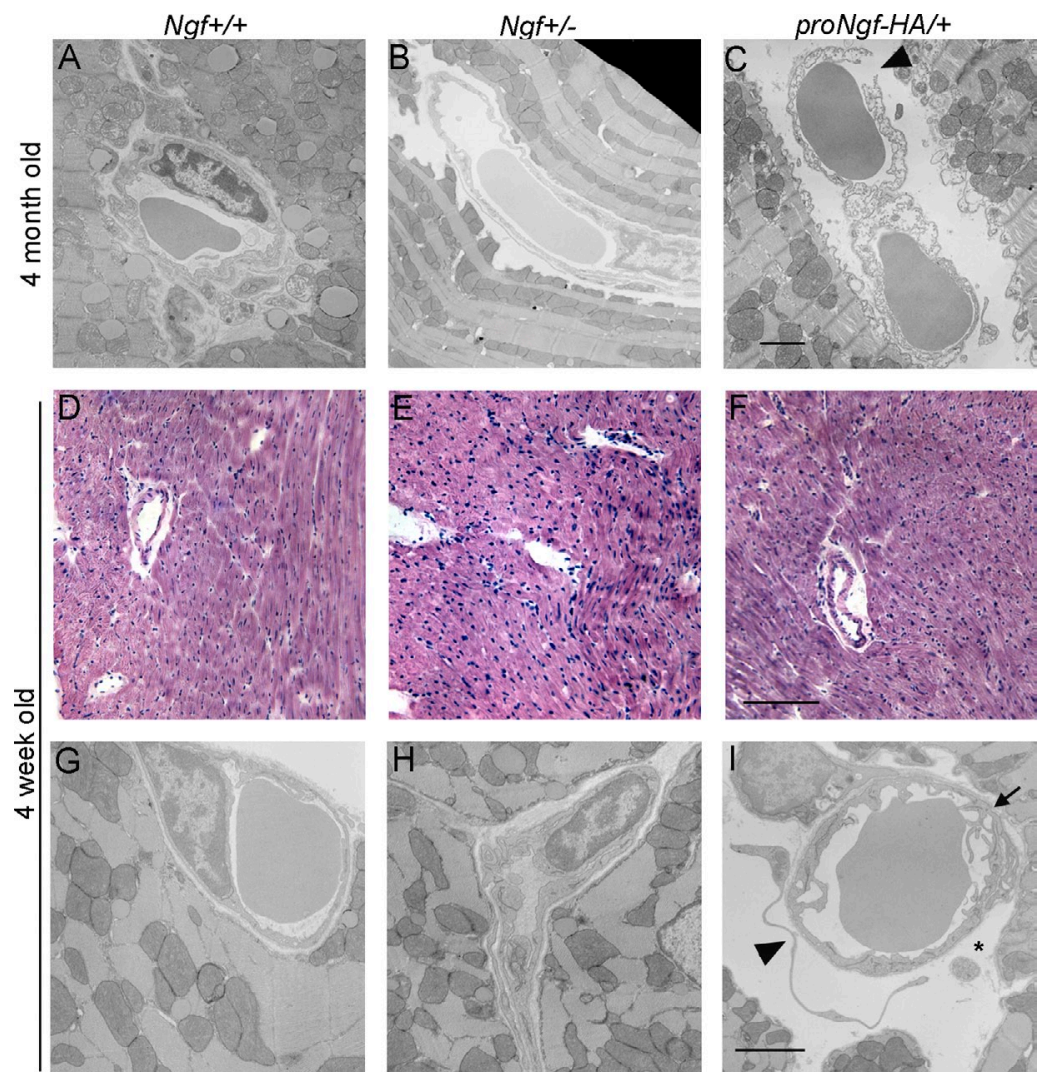

Figure 5. Hearts from adult proNgf-HA/+ mice exhibit microvascular damage and hearts from juvenile proNgf-HA/ ${ }^{+}$mice show early signs of endothelial cell activation and microvascular damage. (A-C) Transmission electron microscopic images of hearts from 4-mo-old $\mathrm{Ngfl}^{++}, \mathrm{Ngft}^{+-}$, and proNgf-HA/+ mice, respectively. Arrowhead, microvascular endothelial cell with fragmented plasma membrane. (D-F) Normal $\mathrm{H}$ and $\mathrm{E}$ histology of 1-mo-old $\mathrm{Ngfl}^{++}, \mathrm{Ngft}^{--}$, and proNgf-HA/+ hearts. (G-I) Representative transmission electron microscope images of hearts from 1-mo-old $\mathrm{Ngft}^{++}, \mathrm{Ngft}^{+-}$, and proNgf-HA/+ mice. Microvascular endothelial cells from proNgf-HA/+ mice exhibit filamentous membrane projections into the vessel lumen (I, arrow). In the proNgf-HA/+ myocardium, $\sim 50 \%$ of microvascular endothelial cells examined showed signs of activation as well as perivascular edema $(I$, asterisk). Additionally, a loss of apposition in the processes of pericyte with endothelial cells is observed (arrowhead). Bars: (A-C and G-I) $2 \mu \mathrm{m}$; (D-F) $100 \mu m . n=2 /$ genotype.
(Fig. $5 \mathrm{C}$ and not depicted). Perivascular edema was prominent in the capillary bed of proNgf-HA/+ mice, as was an increase in caveolae in endothelial cells (Fig. 5 C), observations which were not seen in $\mathrm{Ngf}^{+/+}$or $\mathrm{Ngf}^{t^{\prime-}}$ mice. The abnormalities in endothelial cell morphology were restricted to capillaries because the endothelial cells lining arteries and veins appeared normal (unpublished data). These observations indicate that microvascular damage occurs by early adulthood and are consistent with ultrastructural changes observed in other mouse models of microvascular dysfunction (Hellström et al., 1999).

To determine the time course of functional impairment in proNgf- $\mathrm{HA} /^{+}$mice, we serially examined a cohort of mice from 1.5 to 8 mo of age using transthoracic echocardiography (Fig. $4 \mathrm{~K}$ ). Contractile dysfunction of pro $\mathrm{Ng}-\mathrm{HA} /{ }^{+}$mice was evident at 2 mo of age with a continued decline in pro $\mathrm{Ng}-\mathrm{HA} /{ }^{+}$ mice as compared with control animals (Fig. $4 \mathrm{~K}$, compare $\mathrm{Ng}^{+/+}$[filled blue diamonds; $n=18$ ] to ro $\mathrm{Ngf-HA} /{ }^{+}$[filled red squares; $n=31]$; $\mathrm{P}<0.005)$. Left ventricular posterior wall thickness measured at diastole (LVPWd) and systole (LVPWs) was normal at 2 mo of age in pro $\mathrm{Ng}-\mathrm{HA} /{ }^{+}$mice compared with $\mathrm{Ngf}^{+/+}$littermate controls (LVPWd, $0.7618 \pm$ $0.0963 \mathrm{~mm}$ for proNGF-HA/ ${ }^{+}$vs. $0.7613 \pm 0.131 \mathrm{~mm}$ for $\mathrm{Ngf}^{+/+}$; LVPWs, $1.262 \pm 0.149 \mathrm{~mm}$ for proNGF-HA/ ${ }^{+}$vs. $1.143 \pm 0.223 \mathrm{~mm}$ for $\mathrm{Ng}^{+/+}$, mean $\pm \mathrm{SD}$; proNGF-HA/ $\left.n=16 ; \mathrm{Ngf}^{+/+}, n=7\right)$ but was significantly decreased by 6 mo of age (LVPWd, $0.540 \pm 0.114 \mathrm{~mm}$ for proNGF-HA $/^{+}$vs. $1.010 \pm 0.217 \mathrm{~mm}$ for $\mathrm{Ng}^{+/+}, \mathrm{P}=0.001$; LVPWs, $0.956 \pm$ $0.249 \mathrm{~mm}$ for proNGF-HA/ ${ }^{+}$vs. $1.407 \pm 0.306 \mathrm{~mm}$ for
$\mathrm{Ngf}^{+/+}, \mathrm{P}=0.026$, mean $\pm \mathrm{SD} ;$ proNGF-HA $/^{+}, n=7 ; \mathrm{Ng}^{+/+}$, $n=4$ ), consistent with development of dilated cardiomyopathy. Kaplan-Meier analysis of this cohort of serially imaged animals demonstrated a $50 \%$ mortality rate among the pro Ngf$\mathrm{HA} /{ }^{+}$cohort at $5 \mathrm{mo}$ of age when compared with wild-type $\mathrm{Ngf}^{+/+}$mice (Fig. 4 L). Furthermore, most pro $\mathrm{Ngf-HA} /{ }^{+}$animals died before 8 mo of age as a result of progressive cardiomyopathy, although a minority of animals died before $6 \mathrm{mo}$ of age, or lived to $12 \mathrm{mo}$, consistent with modest variations in disease onset. However, proNgf-HA $/^{+}$mice from three independently targeted embryonic stem cell clones exhibited this cardiac phenotype, which was not observed in $w t \mathrm{Ngf-HA} /^{+}$ mice derived from two independent clones.

\section{Genetic deletion of $p 75$ rescues proNGF-mediated cardiomyopathy}

To determine if proNGF acts through the $\mathrm{p} 75^{\mathrm{NTR}}$ and/or sortilin receptors, we serially examined mice expressing proNGF that were deficient in either $\mathrm{p} 75^{\mathrm{NTR}}\left(p 75^{-/-}\right.$;pro Ngf-HA ${ }^{+}$; $n=14)$ or sortilin (sortilin ${ }^{-\prime} ;$ pro $\left.\mathrm{Ngf}-\mathrm{HA} /^{+} ; n=15\right)$. Using echocardiography, we found that $\mathrm{p} 75^{\mathrm{NTR}}$ deficiency blocked the development of ventricular dilation and fibrosis (Fig. 4, C, F, and I) and cardiac hypocontractility (Fig. 4 K, empty red squares) and prevented premature death (Fig. 4 L). However, sortilin deficiency did not protect proNGF-expressing mice from developing cardiomyopathy (Fig. $4 \mathrm{~K}$, green triangles; and histological data not depicted). Kaplan-Meier analysis demonstrated that $50 \%$ of the sortilin ${ }^{-/} ; p^{-} \mathrm{Ngf}-\mathrm{HA} /^{+}$ 

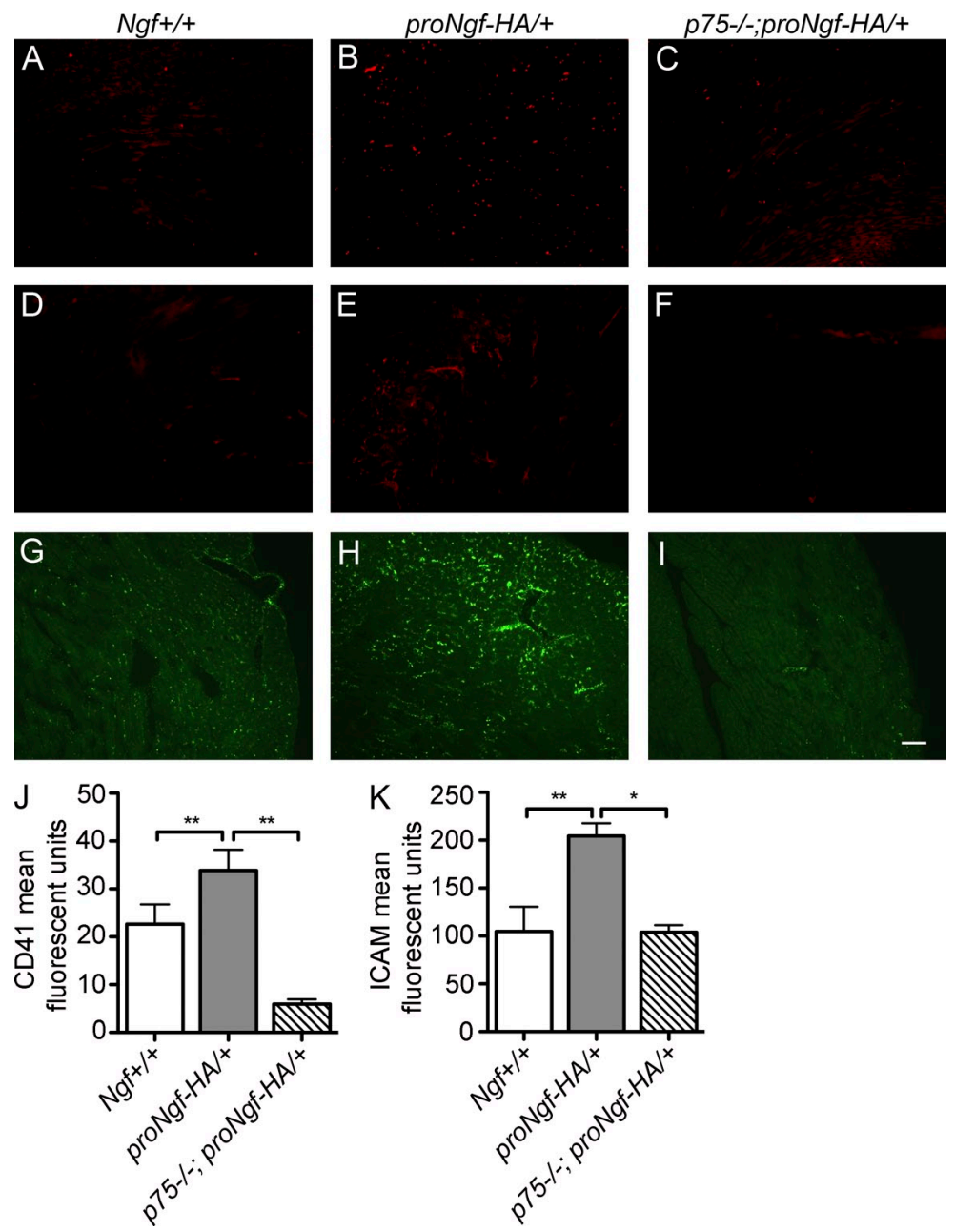

mutant mice died by 4 mo of age, and $>90 \%$ of the remaining mice died by 8 mo of age, comparable to the proNgf- $\mathrm{HA} /^{+}$ mice (Fig. $4 \mathrm{~L}$ ). These results suggest that $\mathrm{p} 75^{\mathrm{NTR}}$ is sufficient to mediate proNGF-induced cardiomyopathy. Analysis of wt $\mathrm{Ngf-HA/^{+ }}$, sortilin ${ }^{-/-}, \mathrm{Ng} f^{+/-}$, and $p 75^{-/-}$mice individually revealed no observable abnormalities in cardiac wall motion (unpublished data). Therefore, these results demonstrate that proNGF expression promotes dilated cardiomyopathy through a process that requires $\mathrm{p} 75^{\mathrm{NTR}}$.

Microvascular endothelial activation and increased vascular permeability precede the development of cardiac fibrosis

To better understand the pathophysiological mechanisms that underlie proNGF:p75 $5^{\text {NTR }}$-mediated cardiomyopathy, we performed histological and ultrastructural analysis of heart tissue obtained from 1-mo-old mice, when cardiac compromise is not yet apparent. Although the hearts of proNgf-HA/ ${ }^{+}$mice have a normal histological appearance (Fig. 5, D-F), ultrastructural analysis ( $n=2$ of each genotype) revealed that microvascular endothelial cells were abnormal in proNgf-HA/ ${ }^{+}$but not in $\mathrm{Ngf}^{+/+}$or $\mathrm{Ngf}^{+/-}$myocardium (Fig. 5, G-I). Morphological changes included many prominent endothelial projections into the capillary lumen (Fig. 5 I, arrow), increased platelet adherence
Figure 6. Abnormalities in the microvasculature of hearts from proNgf-HA/+ mice. (A-C) Hearts from proNgf$\mathrm{HA} /{ }^{+}$mice at postnatal day 9 analyzed for platelet deposition (as assessed by CD41 immunofluorescence, red) compared with $\mathrm{Ngft}^{++}$and with $p 75^{-/-}$; proNgf-HA/+ myocardium. (D-F) ICAM-1 expression (red) in the proNgf-HA/+ myocardium compared with the $\mathrm{Ngft}^{++}$and $\mathrm{p75^{-/- }} ;$ proNgf-HA/+ myocardium, at postnatal day 9. (G-I) FITC-dextran (green) accumulation and extravasation was examined in the myocardium from 3-mo-old proNgf-HA/ ${ }^{+}, \mathrm{Ngf+}++$ and $\mathrm{p} 75^{-/-}$; proNgf-HA/ ${ }^{+}$mice. (J and $\mathrm{K}$ ) Quantification of CD41 and ICAM-1 immunofluorescence ( $n=3-6$ mice/condition, eight fields of view per mouse). ${ }^{*}, \mathrm{P}<0.05 ;{ }^{* *}, \mathrm{P}<0.01$, mean \pm SEM. Bar, $100 \mu \mathrm{m}$. to the activated microvascular endothelial cells, and deposits of fibrin strands in the lumen of capillaries (not depicted). Some capillaries in the proNgf-HA/ ${ }^{+}$ventricular myocardium exhibited perivascular edema with a loss of close apposition of endothelial cells to the extracellular matrix (3/16 vessels examined; Fig. 5 I, asterisk), which was not observed in control mice. In addition, a loss of apposition in the processes of pericytes with endothelial cells was observed in the proNgf-HA/ ${ }^{+}$mice (Fig. 5 I, arrowhead). Abnormalities in microvascular endothelial cells in pro $\mathrm{Ngf-HA} /{ }^{+}$mice at 1 mo of age were extensive, as 40/75 endothelial cells examined at the ultrastructural level exhibited one or more signs of activation, in contrast to $<5 \%$ of microvascular endothelial cells in hearts of control mice.

Biochemical and immunohistological changes were also evident in the microvasculature of proNgf-HA/ $/^{+}$mice. Increased platelet accumulation, detected by $\mathrm{CD} 41^{+}$immunoreactivity, was observed in the proNgf-HA/ ${ }^{+}$ventricular myocardium when compared with wild-type littermates (Fig. 6, A and B). This phenotype was rescued in $p 75^{-1-}$; pro Ngf- $\mathrm{HA} /^{+}$animals (Fig. $6 \mathrm{C}$, quantified in Fig. $6 \mathrm{~J}$ ). Focal increase in intercellular adhesion molecule (ICAM) immunoreactivity was also observed in the proNgf- $\mathrm{HA} /{ }^{+}$mice as compared with $\mathrm{Ng} f^{+/+}$mice, again suggesting endothelial cell activation (Fig. 6, D and E). 

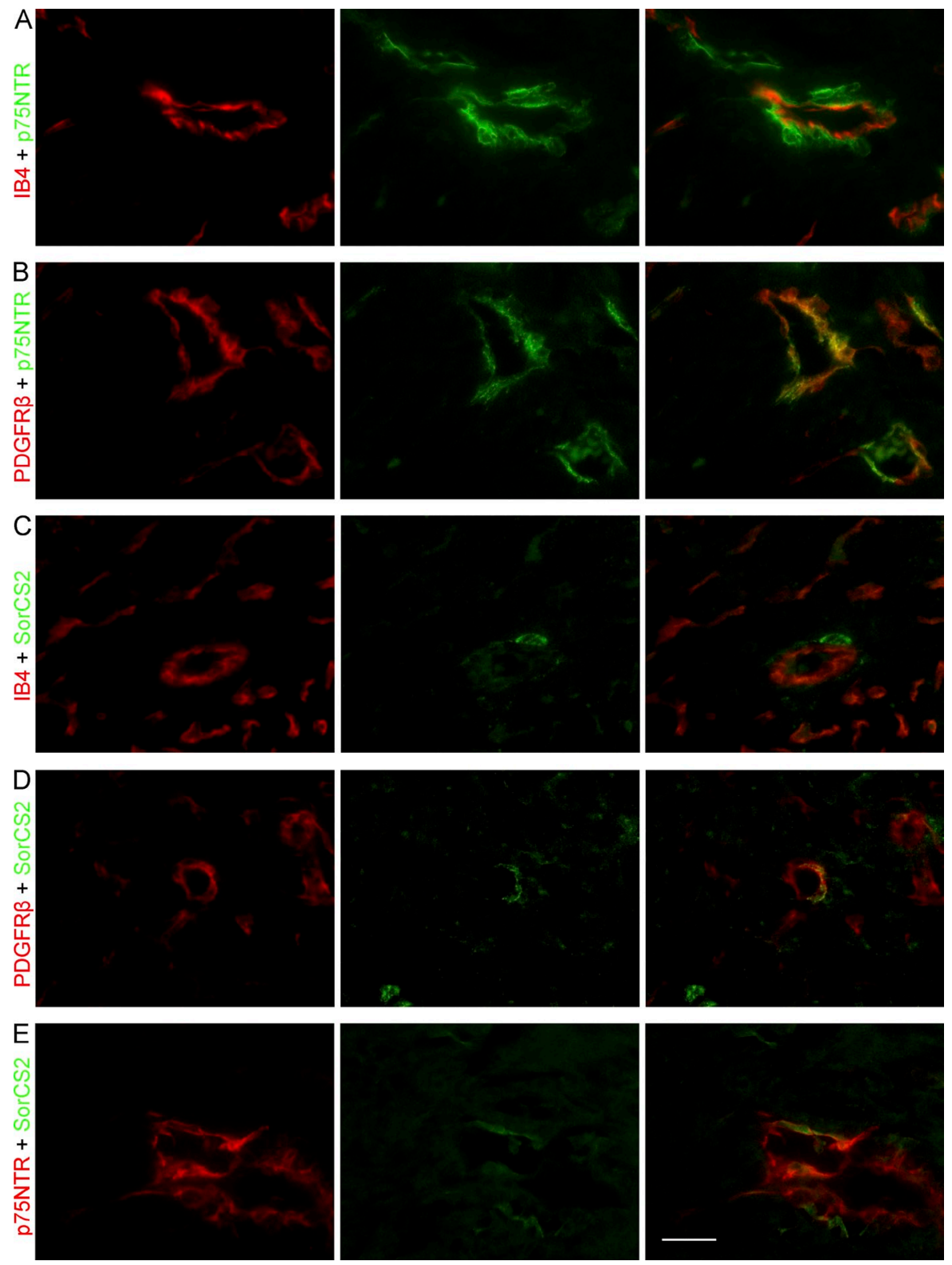

Figure 7. Expression of proNGF receptors during cardiac vessel development. E18.5 ( $A, B$, and E) or E20.5 (C and D) C57BL6/J embryos were analyzed for $\mathrm{p} 75^{\mathrm{NTR}}$ and SorCS2 immunoreactivity (hearts from $\mathrm{Ng}^{+/+}$ and proNgf-HA/+ embryos yielded similar results). ( $A$ and $B$ ) p75 NTR (green) does not colocalize with IB4 (red) on endothelial cells (A) but does colocalize with PDGFR- $\beta$ (red), which labels pericytes (B). (C and D) SorCS2 immunoreactivity (green) is detected on a subset of PDGFR- $\beta$-immunopositive pericytes (red) at E20.5 but not on IB4+ endothelial cells (red). (E) p75 NTR and SorCS2 are colocalized on some pericytes at E18.5. Single channel and overlays are shown. Bar, $25 \mu \mathrm{m}$. $n=3$ mice per age.
Furthermore, increased ICAM expression was reversed in proNgf-HA $/^{+}$mice deficient in $\mathrm{p} 75^{\mathrm{NTR}}$ (Fig. $6 \mathrm{~F}$, quantified in Fig. $6 \mathrm{~K})$. Although $\mathrm{CD}^{+} 8^{+}$histiocytes have infiltrated extensively in the aged pro $\mathrm{Ng}-\mathrm{HA} /^{+}$hearts, the number of infiltrating $\mathrm{CD} 45^{+}$leukocytes and $\mathrm{Gr}^{+}$granulocytes were unchanged at early ages (4 wk of age) in the hearts of pro $\mathrm{Ngf-HA}{ }^{+}$mice compared with $\mathrm{Ng} f^{+/+}$littermates (unpublished data). Lastly, perfusion studies using FITC-dextran $(70 \mathrm{kD})$ in 3-mo-old mice demonstrated increased extravasation in the hearts of proNgf-HA/ ${ }^{+}$mice. This is in contrast to low levels of dextran particle extravasation seen in the hearts of the $\mathrm{Ng} f^{+/+}$mice and p75 ${ }^{-/-}$;proNGF-HA/ ${ }^{+}$(Fig. 6, G-I). Collectively, these results strongly suggest that proNGF targets $\mathrm{p} 75^{\mathrm{NTR}}$ to induce cardiac microvascular endothelial cell activation and enhanced vascular permeability in early postnatal development.
Surprisingly, we were unable to detect $\mathrm{p} 75^{\mathrm{NTR}}$ in the cardiac microvasculature or in cardiac myocytes by immunofluorescence microscopy in mice from 1 to 4 wk of age (unpublished data), despite immunological and ultrastructural evidence of microvascular damage in the proNgf-HA/ ${ }^{+}$mice. However, immunofluorescence microscopy confirmed the colocalization of $\mathrm{p} 75^{\mathrm{NTR}}$ and PDGFR- $\beta$ in perinatal hearts (Fig. 7, A and B), supporting our hypothesis formulated from the cardiac I-R studies (Fig. 2 B) that PDGFR- $\beta$-expressing pericytes are the target of cardiac myocyte-derived proNGF. Furthermore, we detected SorCS2 expression in a subpopulation of PDGFR $-\beta^{+} / \mathrm{p} 75^{\mathrm{NTR}+}$ pericytes (Fig. 7, D and E; and not depicted) in the perinatal heart.

To elucidate the effects of proNGF on pericytes in the perinatal heart, we used NG2DsRedBAC-transgenic mice, which express the red fluorescent protein DsRed under the control of 

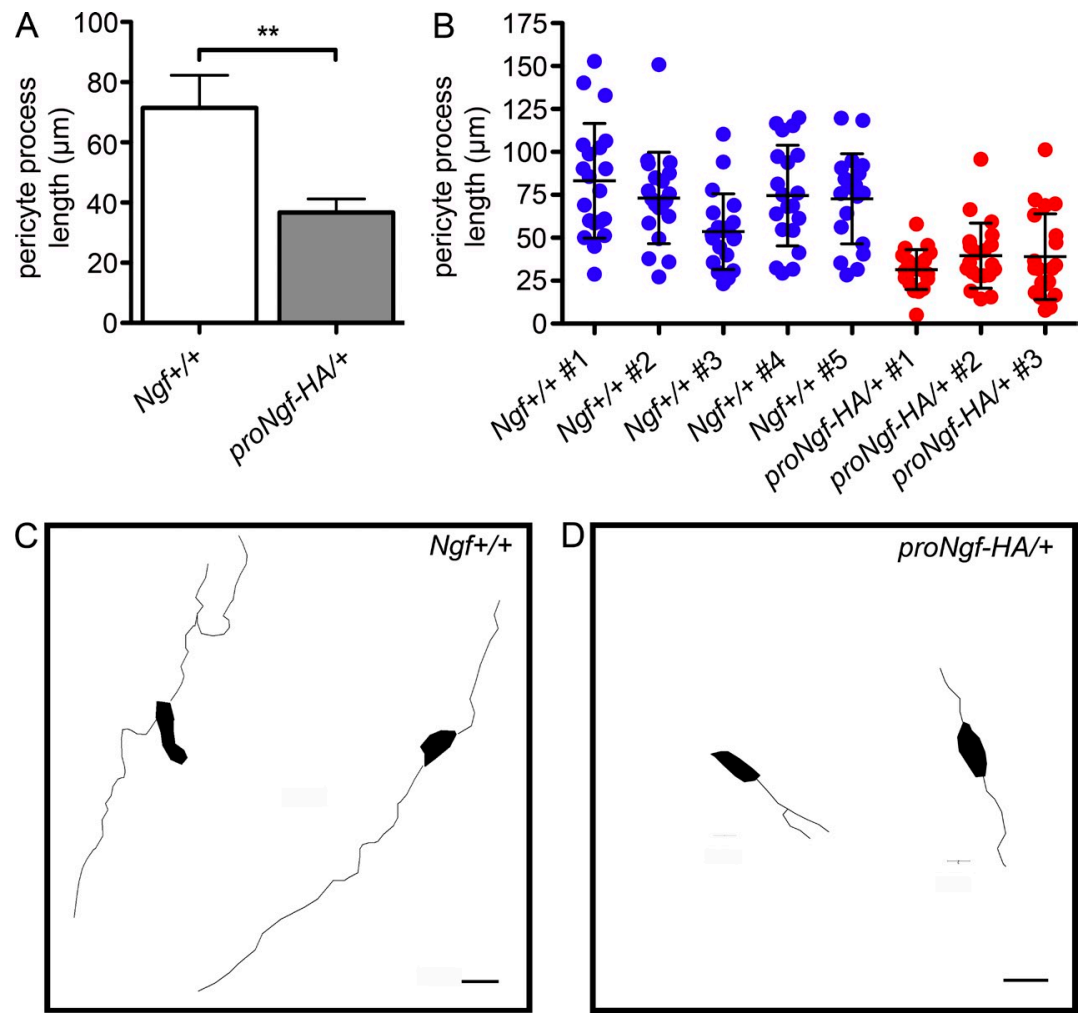

Figure 8. Decreased pericyte process length in the hearts of 1-mo-old pro $\mathrm{Ngf}-\mathrm{HA} /{ }^{+}$mice. (A) Mean pericyte process length in the hearts of 1-mo-old NG2dsRedBAC; proNgf-HA/+ mice compared with NG2dsRedBAC; Ngft/+ littermates (**, P $<0.01$, mean $\pm S D$ ). (B) Pericyte process length from each individual animal analyzed. 20 pericytes per animal were measured. Pericytes from $\mathrm{Ng}^{+/+}$mice are shown in blue and proNgf-HA/+ are shown in red (mean $\pm \mathrm{SD}$ ). ( $C$ and D) Representative tracings of pericytes from NG2dsRedBAC; $\mathrm{Ng}^{+/+}$mice (C) and NG2dsRED; proNgf-HA/+ mice (D). Bars, $5 \mu \mathrm{m}$. Ngft/+,$n=5$; proNgf-HA/ ${ }^{+}, n=3$. the Cspg4 promoter, allowing selective detection of pericytes and smooth muscle cells in the periphery (Zhu et al., 2008; Lebrin et al., 2010). These mice were crossed with the proNgf-HA/ ${ }^{+}$mice to generate NG2DsRedBAC; proNgf-HA/+ mice. Using a morphometric approach, we quantitated pericyte process length in 1-mo-old NG2DsRedBAC; proNgf-HA/ ${ }^{+}$ mice and NG2DsRedBAC; $\mathrm{Ng}^{+/+}$littermates. Pericytes from NG2DsRedBAC; proNgf- $H A /^{+}$mice had significantly shorter pericyte processes compared with NG2DsRedBAC; $\mathrm{Ng}^{+/+}$ littermate control mice (Fig. 8). These data suggest that proNGF targets $\mathrm{p} 75^{\mathrm{NTR}}$ present on perinatal pericytes to decrease pericyte process length and therefore reduce pericyte coverage of the cardiac microvasculature.

These observations support the hypothesis that up-regulation of $\mathrm{p} 75^{\mathrm{NTR}}$ and SorCS2 in pericytes in the peri-infarct myocardium (Fig. 1, B-E) may be an important step in the induction of microvascular endothelial pathology by reducing pericyte process length and coverage of the microvasculature. Collectively, these studies suggest that proNGF activation of $\mathrm{p} 75^{\mathrm{NTR}}$ and SorCS2 receptors on pericytes impairs mechanical and trophic support of microvascular endothelial cells, leading to endothelial activation, platelet adhesion, enhanced vascular permeability, and ultimately cardiac fibrosis.

\section{p75 ${ }^{\text {NTR }}$ deficiency provides protection from infarct expansion}

To determine if proNGF/p $75^{\text {NTR }}$ signaling modulates microvascular dysfunction and the expansion of infarct size after myocardial I-R injury, we measured infarct size in wild-type and $p 75^{-1-}$ mice $10 \mathrm{~d}$ after reperfusion. Infarct size was quantified after Masson's trichrome staining and normalized to the area at risk. Infarct size was significantly smaller in $p 75^{-1-}$ mice compared with wild-type mice (Fig. 9). These results suggest that elevated proNGF, acting through the receptor $\mathrm{p} 75^{\mathrm{NTR}}$ induced in pericytes after I-R, may contribute to post-MI microvascular deficiency and increase of infarct size. We have previously demonstrated that infarct size is not different $24 \mathrm{~h}$ after I-R in $p 75^{-/-}$mice compared with wild-type mice (Lorentz et al., 2011). However, analysis of infarct size $24 \mathrm{~h}$ after I-R injury primarily measures the area of necrosis induced by cardiac ischemia, whereas the expression of $\mathrm{p} 75^{\mathrm{NTR}}$ and proNGF are maintained for several days (unpublished data). Collectively, these results suggest that $\mathrm{p} 75^{\mathrm{NTR}}$ is not directly involved in the necrotic lesion induced by I-R but rather plays a role in infarct expansion via microvascular injury.

\section{DISCUSSION}

Events that lead to persistent cardiac microvascular compromise after transient ischemic injury remain incompletely understood (Eltzschig and Collard, 2004; Bekkers et al., 2010). Early studies demonstrated impaired microvascular perfusion which led to the proposal that luminal obstruction by thromboembolic debris and endothelial cell edema is the main cause of the pathology observed (Kloner et al., 1974). However, it is now established that inflammatory cytokines play a crucial role in initiating microvascular damage (Nian et al., 2004). Cytokines such as TNF, IL-1, and IL-6 are induced soon after myocardial ischemia, triggering leukocyte transmigration, platelet adhesion, and local generation of reactive 
A
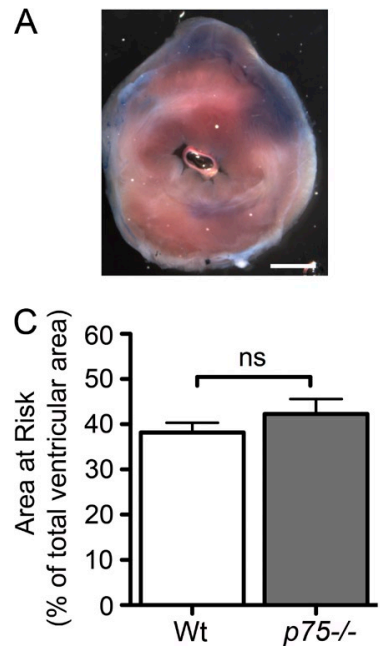

B
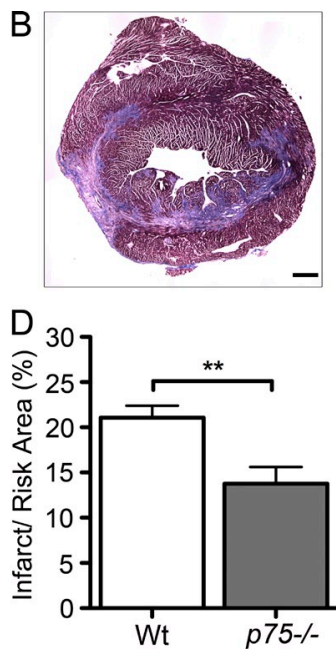

Figure 9. Infarct size is reduced in $\mathrm{p} 75^{\mathrm{NTR}}$ deficient mice $10 \mathrm{~d}$ after I-R surgery. (A) Representative picture of a 1-mm heart section showing the area at risk determined by re-ligation of the left anterior coronary artery $10 \mathrm{~d}$ after surgery and perfusion with Evans blue dye. The area at risk is devoid of blue dye. (B) Representative picture of a Masson's trichrome stain to identify the infarcted region of the heart $(0.5 \mathrm{~mm}) 10 \mathrm{~d}$ after surgery. (C) The area at risk (percentage of total ventricular volume), determined by perfusion with Evans blue dye in $p 75^{-1-}$ mice compared with wild-type mice. (D) Infarct size normalized to the area at risk in $p 75^{-1-}$ mice compared with wild-type $10 \mathrm{~d}$ after $\mathrm{I}-\mathrm{R}$ surgery. ${ }^{*}, \mathrm{P}<0.01$, mean \pm SEM, $n=5-6$ mice/ genotype. Bars: (A) $1 \mathrm{~mm}$; (B) $0.5 \mathrm{~mm}$.

oxygen species (Springer, 1994; Panés et al., 1999). In the present study, we determined that proNGF acts as a cytokine and a potent mediator of I-R injury by activating the $\mathrm{p} 75^{\mathrm{NTR}}$ receptor. Although certain inflammatory cytokines can lead to beneficial post-infarct remodeling (Nian et al., 2004), the effects of proNGF are deleterious, causing microvascular damage, compromising cardiac function, and eventually resulting in cardiomyopathy.

ProNGF, like the proinflammatory cytokines TNF, IL-1, and IL-6, is not constitutively expressed in the normal heart but is up-regulated as an intrinsic or innate response to injury or ischemia (Kapadia et al., 1997; Mann, 2003). Similar to TNF, proNGF binds and activates a TNF receptor superfamily member, $\mathrm{p} 75^{\mathrm{NTR}}$ (also known as TNFRSF16), that encodes a cytoplasmic death domain. Ligand-activated $\mathrm{p} 75^{\mathrm{NTR}}$ recruits signaling proteins including TRAF6, RIP2, and TRADD, which are used by other TNFR family members (Gentry et al., 2004; Teng et al., 2010). Signaling by p $75^{\text {NTR }}$, which has been most extensively studied in neurons, ultimately results in activation of JNK and caspase-3 and can lead to neuronal death (Volosin et al., 2008). Other studies have implicated $\mathrm{p} 75^{\mathrm{NTR}}$ in regulating fibrinolysis in the nervous system, although the ligands that mediate this effect have not been identified (Sachs et al., 2007). The results presented here suggest that proNGF elicits a proinflammatory state in the myocardium, promoting leukocyte recruitment, endothelial activation, and extracellular matrix deposition, although further studies will be required to determine whether all of these

effects are direct or result from cytokine amplification after transmigration of leukocytes.

One important aspect of our study is the identification of p $75^{\mathrm{NTR}}$-expressing pericytes as the cell type activated by proNGF. This observation underscores the critical role of pericytes to establish and maintain stabilization of the cardiac microvasculature (Gaengel et al., 2009). Pericytes release cytokines locally to induce endothelial cells to exit the cell cycle and differentiate via angiopoietin-1:Tie2 signaling (Dumont et al., 1994; Sato et al., 1995; Suri et al., 1996). Conversely, endothelial cells produce TGF- $\beta$ that locally activates Alk5 on pericytes to stimulate proliferation and differentiation (Oh et al., 2000; Larsson et al., 2001). These reciprocal interactions promote pericyte ensheathment to stabilize endothelial junctions and reduce vascular permeability. Most studies of pericyteendothelial cell interactions focus on developmental time points (Armulik et al., 2005). This study identifies a subpopulation of cardiac pericytes that transiently express $\mathrm{p} 75^{\mathrm{NTR}}$ in late gestation, although expression is down-regulated postnatally.

The current studies support the hypothesis that after ischemia, cardiomyocyte-derived proNGF, acting through $\mathrm{p} 75^{\mathrm{NTR}}$ which is induced by pericytes, causes pericyte injury and pericyte process retraction, resulting in a lack of trophic support of the microvascular endothelium. Indeed, the ultrastructural abnormalities observed in the proNgf-HA/ ${ }^{+}$mice, which include increased caveolae, numerous luminal projections, loss of apposition of pericytes and endothelial cells, and perivascular edema, are highly reminiscent of the ultrastructural changes in mice deficient in pericytes (Lindahl et al., 1997; Hellström et al., 1999). Furthermore, vessel damage in the proNGF-expressing heart is restricted to capillaries, precapillary arterioles, and postcapillary venules, with normal coronary arteries and veins. This pattern corresponds to vessels with pericyte ensheathment (Allt and Lawrenson, 2001). Although proNGF induces apoptosis of $\mathrm{p} 75^{\mathrm{NTR}}$-expressing neurons in other injury models, we did not detect overt pericyte apoptosis. This may reflect difficulties in quantitating pericyte loss, as pericyte coverage of the abluminal endothelium is estimated to be only $10-20 \%$ in the cardiac microvasculature (Shepro and Morel, 1993). However, proNGF-induced activation of $\mathrm{p} 75^{\mathrm{NTR}}$-expressing pericytes may induce more subtle effects, such as process retraction, to reduce pericyte ensheathment. Indeed, examination of pericyte process length revealed shorter pericyte processes in the proNgf-HA/ ${ }^{+}$mice compared with littermate control mice, suggesting that inhibition of pericyte process outgrowth or process retraction is occurring when cardiac proNGF levels are elevated. These data are reminiscent of neuronal studies in which proNGF induces growth cone collapse (Deinhardt et al., 2011) and proBDNF, a related proneurotrophin ligand, induces retraction of $\mathrm{p} 75^{\mathrm{NTR}}$-expressing neuronal processes (Koshimizu et al., 2009; Yang et al., 2009). Collectively these data suggest that proNGF activation of pericytes expressing $p 75^{\text {NTR }}$ results in endothelial cell activation, leukocyte transmigration, fibrin and platelet deposition, and microvascular thrombosis, culminating in myocardial ischemia and fibrosis. 
These findings are consistent with prior reports of local microvascular loss that result in dilated cardiomyopathy (Roura and Bayes-Genis, 2009). The current study strongly suggests that pericytes play a crucial role in maintaining microvascular function after ischemic injury.

ProNGF has been best characterized as a cytokine induced after neuronal injury in the central and peripheral nervous systems (Hempstead, 2009). Under these conditions, proNGF promotes neuronal apoptosis, and infusion of function-blocking antibodies specific for proNGF rescues most $\mathrm{p} 75^{\mathrm{NTR}}$-expressing neurons after central neuron axotomy or seizures (Harrington et al., 2004; Volosin et al., 2006). Results presented here extend the pathological actions of proNGF to include induction of vascular injury after $\mathrm{MI}$ in humans and cardiac I-R injury in mice. The coordinate up-regulation of proNGF and p $75^{\text {NTR }}$ within $24 \mathrm{~h}$ after I-R injury (Hiltunen et al., 2001; Hasan et al., 2006; this paper) is consistent with the rapid induction observed in the central nervous system. The progressive decrease in cardiac contractility in pro $\mathrm{Ngf}-\mathrm{HA} /{ }^{+}$mice, but not $\mathrm{Ngf}^{+/-}$mice, indicates that sustained levels of proNGF, rather than haploinsufficiency of mature NGF, induces cardiac microvascular dysfunction.

Genetic experiments defined the critical role of $\mathrm{p} 75^{\mathrm{NTR}}$ in mediating microvascular damage in the proNGF-expressing mouse. Indeed, mice deficient in p $75^{\mathrm{NTR}}$ exhibit a reduction in infarct size normalized to area at risk at $10 \mathrm{~d}$ after I-R injury. These results indicate that the cardiac microvasculature, like peripheral and central neurons, utilizes $p 75^{\mathrm{NTR}}$ as the critical signaling component of the proNGF receptor complex. Although sortilin is a coreceptor for proNGF in neurons, and genetic deletion of sortilin rescues some classes of neurons from proNGF-induced apoptosis (Jansen et al., 2007), it was not involved in proNGF-induced cardiomyopathy. Conversely, SorCS2 may substitute for sortilin as the relevant $\mathrm{p} 75^{\mathrm{NTR}}$ coreceptor in the cardiac vasculature. This conclusion is based on the findings that SorCS2 binds to proNGF in heterologous cells, is expressed in pericytes of the perinatal heart and is induced in the human and mouse vasculature after injury.

In summary, our work provides strong evidence that proNGF is induced in the ischemic heart and binds the $\mathrm{p} 75^{\mathrm{NTR}}$ receptor to promote pathological changes in the microvasculature that ultimately result in cardiomyopathy. This finding identifies proNGF and the $\mathrm{p} 75^{\mathrm{NTR}}$ receptor as relevant targets for therapeutic strategies to protect the microvasculature after ischemic injury. Interventional therapy aimed at blocking the actions of proNGF on $\mathrm{p} 75^{\mathrm{NTR}}$-expressing pericytes may prove successful in preventing microvascular damage after myocardial ischemia. Furthermore, the induction of proNGF and p $75^{\text {NTR }}$ after $1-2 \mathrm{~d}$ of ischemic injury in rodents provides a window of opportunity for accurate diagnosis and delivery of agents to impair proNGF or $\mathrm{p} 75^{\mathrm{NTR}}$ activation in patients who have suffered from myocardial ischemia.

\section{MATERIALS AND METHODS}

Human tissue samples. Donated cardiac tissue was collected at autopsy performed by the Department of Pathology, Weill Cornell Medical College, and sections from de-identified blocks of formalin-fixed paraffin-embedded tissues were used. All experimental protocols were approved by the Human Research Protections Program at Weill Cornell involving human subject research. MI typically involved the left ventricle. Control heart tissue was from subjects without acute myocardial disease and with similar demographic criteria. The patient characteristics are described in Table S1.

Immunohistochemistry was performed using $10-\mu$ m-thick sections of formalin-fixed paraffin-embedded samples. Sections were deparaffinized in xylene and rehydrated in graded alcohols before incubation in phosphatebuffered saline. Slides were then incubated in a steamer in $10 \mathrm{mmol} / \mathrm{liter}$ citrate buffer (10 mmol/liter citric acid monohydrate, $\mathrm{pH}$ 6.0, 0.05\% Tween 20) for $30 \mathrm{~min}$ to recover antigenic epitopes. Slides were probed with IgG-cut or affinity purified polyclonal rabbit antibodies specific to the prodomain of ProNGF, the intracellular domain of $\mathrm{p} 75^{\mathrm{NTR}}$, or the intracellular domain of SorCs2. Bound antibodies were detected with a biotinylated-conjugated secondary antibody system (Jackson ImmunoResearch Laboratories) and VIP development according to the manufacturer's protocol (red stain; Vector Laboratories). Developed slides were counterstained in hematoxylin (purple stain), dehydrated through graded alcohols, incubated in Xylene, and mounted in CytoSeal (Thermo Fisher Scientific). Slide images were captured with an Observer.Z1 (Carl Zeiss) and digital images were acquired with an AxioCam MRc camera and AxioVision 4.8. ProNGF immunoreactivity in cardiomyocytes was quantified using a semiquantitative method in which 10 fields of view were scored by a blinded individual. Each field of view was given a score of 0-4: 0 for absence of immunoreactivity, 1 for weak immunoreactivity, 2 for modest immunoreactivity, 3 for moderate immunoreactivity, and 4 for strong immunoreactivity. The number of fields of view from noncardiac patients (control) and from the peri-infarct region of MI that were scored as $0,1,2,3$, or 4 was averaged. ProNGF and p $75^{\text {NTR }}$ immunoreactivity in blood vessels was quantified by counting the number of positive or negative vessels.

Inducible knockin mouse generation, breeding, and characterization. All procedures were approved by the Weill Cornell Medical College Institutional Animal Care and Use Committee. Genomic PAC clone RPCI21494-C12 was identified from a 129/SvevTACfBR female spleen library purchased from the UK HGMP MRC Geneservice using standard dot blotting techniques (Osoegawa et al., 2000). The HA epitope tag was added by sitedirected mutagenesis in-frame before the stop codon. The furin recognition site was mutated using site-directed mutagenesis (Agilent Technologies) from residues $\mathrm{K}^{120} \mathrm{R}^{121}$ to AA. A modified neomycin-resistance cassette, consisting of (from $5^{\prime}$ to $3^{\prime}$ ) frt-loxp-engrailed splice acceptor-pGK-neo ${ }^{\mathrm{r}}$-stop codon-frt-loxp sequences, was inserted 350 bp upstream from the start codon. A diphtheria toxin cassette was used for positive selection. Three positive independently derived clones expressing prongf- $\mathrm{HA}$ (called pro $\mathrm{Ngf-HA}{ }^{+}$in this paper) were expanded and microinjected into C57BL/ 6 embryos. Three independent lines of pro $\mathrm{Ngf-HA} /{ }^{+}$mice were obtained in this manner. Two lines of $n g f-H A$ knockin mice (called $w t N g f-H A /^{+}$) were generated in the same manner, except the furin cleavage site was not mutated in this construct. All strains were backcrossed onto a C57BL/6 background for more than eight generations before analysis. Characterization of these mice is detailed the next section.

Genotyping, breeding, tissue processing, and characterization of knockin mice. To identify gene-targeted mice, both Southern blotting and PCR analysis were used to distinguish between the knocked-in allele and the wild-type locus. Specifically, mice containing the HA-tag were identified by amplifying the HA epitope tag using the following primers: 5'-TGAAGCCCACTGGACTAAACTT-3' and 5'-AATCTGGAACATCGTATGGG-3'. Mice that were identified to contain the HA tag were further genotyped to distinguish between those containing the mutated NGF furin cleavage site versus those containing the wild-type furin cleavage site using the following primers: 5'-AGGACTCACCGGAGCAAGCGC-3', 5'-AGGACTCACCGGAGCGCGGCC-3' , and 5'-GGAACATCGTATGGGTAGCCTC-3'. The presence of the neomycin resistance cassette was 
verified using a second pair of PCR primers specific for the neomycinresistant gene of bacteria: 5'-GAGATCCACTAGTTCTAGCCTCGAG-3' and 5'-CCCACACACTGACACTGTCACAC-3'.

A chicken $\beta$-actin-cre deleter mouse strain (Sakai and Miyazaki, 1997) was used to remove the neo-resistance cassette, thus permitting expression of the knocked-in allele under its endogenous $n g f$ gene promoter elements. The following primer pairs were used to identify the presence of the crerecombinase allele in mice: $5^{\prime}$-TTATAACACCCTGTTACGTATAGCC-3'

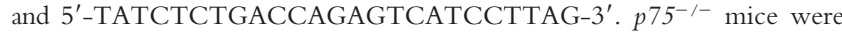
purchased from The Jackson Laboratory and backcrossed to C57BL/6(J) mice until the N8 generation before breeding with other mouse strains. NG2DsRedBAC mice (Zhu et al., 2008) were also purchased from The Jackson Laboratory and were crossed to the $p r o \mathrm{Ngf}-\mathrm{HA} /{ }^{+}$mice to generate NG2DsRedBAC; proNgf-HA/ $/^{+}$mice and NG2DsRedBAC; $\mathrm{Ngf}^{+/+}$littermate control mice for pericyte process analysis. Other control strains include $\mathrm{Ngf}^{+/-}$(Crowley et al., 1994) and sortilin ${ }^{-/-}$(Jansen et al., 2007) genetargeted mice. All strains were backcrossed to a C57BL/6(J) background for at least eight generations.

For immunohistochemical analysis, embryonic or perinatal tissues/organs were fixed overnight in $4 \%$ paraformaldehyde at $4{ }^{\circ} \mathrm{C}$ and then cryoprotected with $30 \%$ sucrose. Adult hearts were similarly processed and cryoprotected with sucrose before embedding in OCT $/ 30 \%$ sucrose (1:1; Sakura). For protein and RNA analyses, heart tissues were stored at $-80^{\circ} \mathrm{C}$ until processing. To analyze vascular permeability, FITC-dextran (70 kD; Sigma-Aldrich) was injected as a bolus through the tail vein of 3-mo-old mice (Camilleri et al., 1983). After perfusion for $10 \mathrm{~min}$, the animals were sacrificed and their hearts were harvested and processed for immunofluorescence microscopy. Masson's trichrome demonstration of collagen deposition was performed according to the manufacturer's instructions (PolyScientific R\&D Corp.) on cryosections. Quantification of cardiac fibrosis was performed using ImageJ (National Institutes of Health). Three to four fields of view from the subendocardium of the heart were analyzed from two to three $10 \mu \mathrm{m}$ sections from mice 6-8 mo of age. In brief, a binary image was generated using Photoshop (Adobe), and blue pixels were converted to white pixels whereas pixels of all other colors were converted to black. The area of fibrosis (white pixels) was measured using a set threshold (ImageJ) and normalized to the total area of tissue in the field of view. RT-PCR was performed according to standard protocols and reagents (Invitrogen) using the HA primers described. The NGF Emax kit (Promega) was used for all ELISA measurements, according to the manufacturer's instructions.

Immunoprecipitation/Western blotting. Frozen hearts and brains were homogenized in lysis buffer $(0.1 \mathrm{M}$ Tris, $\mathrm{pH} 7.4 / 1 \%$ Triton X-100/0.1\% NP-40/0.05\% SDS/10\% glycerol/protease inhibitor cocktail [Sigma-Aldrich]). Proteins tagged by an HA epitope were enriched by binding to an anti-HA antibody (Sigma-Aldrich) at $4^{\circ} \mathrm{C}$. Protein A-Sepharose beads (Sigma-Aldrich) were added to capture the immune complex, washed extensively, and boiled in SDS-PAGE buffer. Blotted proteins were detected using HA.11 monoclonal antibody (Covance) and developed with enhanced chemiluminescence (GE Healthcare). 293T cells were transfected using pcDNA3.1 constructs expressing N-terminal HA-tagged and C-terminal FLAG-tagged mouse proNGF, and/or N-terminal myc-tagged human sortilin and SorCS2 (provided by Z.Y. Chen and F.S. Lee, Weill Cornell Medical College). The myc epitope tags were inserted after the propeptide cleavage site to ensure the expression of the tag. Cell lysates were immunoprecipitated and Western blotted using an antibody to FLAG conjugated to protein A-Sepharose beads (Sigma-Aldrich). The myc-tagged sortilin or SorCS2 proteins were detected using a rabbit anti-myc antibody (Covance) and the HA-tagged proNGF was detected with mouse anti-HA (Covance).

Gelatin zymography. The presence of metalloproteinase activity in mouse hearts was determined using enzyme zymography, as previously described (Pavlovic et al., 2006). Cardiac tissues were snap frozen in liquid nitrogen, pulverized, and extracted with $0.5 \mathrm{ml}$ lysis buffer $(50 \mathrm{mM}$ Tris, $150 \mathrm{mM} \mathrm{NaCl}$, and $1 \%$ Triton $\mathrm{X}-100, \mathrm{pH} 7.5)$ containing a cocktail of protease inhibitors.
The extracts were centrifuged $(14,000 \mathrm{rpm}$ for $15 \mathrm{~min})$ at $4^{\circ} \mathrm{C}$ to remove insoluble debris, and the supernatants were collected for matrix metalloproteinase analysis. Equal amounts of supernatant $(80 \mu \mathrm{l} ; 20 \mu \mathrm{g})$ were mixed with $20 \mu \mathrm{l} 5 \times$ SDS sample buffer (without mercaptoethanol) and incubated for $30 \mathrm{~min}$ at $37^{\circ} \mathrm{C}$. Samples and molecular weight markers were electrophoresed in a $10 \%$ polyacrylamide gel containing $0.25 \%$ gelatin. The gel was then washed $(2 \times)$ in $2.5 \%$ Triton-X 100 to remove SDS, incubated at $37^{\circ} \mathrm{C}$ for $18 \mathrm{~h}$ in $200 \mathrm{mM} \mathrm{NaCl}$ containing $40 \mathrm{mM}$ Tris-HCL and $10 \mathrm{mM} \mathrm{CaCl}$, $\mathrm{pH}$ 7.5, and stained with Coomassie Blue. The presence of gelatinolytic activity was identified as clear bands on a uniform blue background after destaining.

Immunohistochemistry and immunofluorescence. Cryostat sections of heart tissues were fixed in acetone $\left(-20^{\circ} \mathrm{C}\right)$ or in $4 \%$ paraformaldehyde (at room temperature) for $10 \mathrm{~min}$. For immunohistochemistry, sections were treated for $30 \mathrm{~min}$ in $0.1 \% \mathrm{H}_{2} \mathrm{O}_{2} /$ methanol at $-20^{\circ} \mathrm{C}$, and then blocked $(5 \%$ serum of host of secondary antibody $/ 5 \%$ nonfat dry milk/ $0.1 \%$ Triton $\mathrm{X}-100 / \mathrm{PBS}$ ) and incubated with primary antibody overnight at $4^{\circ} \mathrm{C}$. The primary antibodies used were: $\mathrm{p} 75^{\mathrm{NTR}}$ (extracellular domain-directed: R\&D Systems, 1:1,000; intracellular domain-directed: Promega, 1:500), proNGF (prodomain-specific, 1:100; Harrington et al., 2004), sortilin (R\&D, 1:400), SorCS2 (intracellular domain-directed: generated by immunizing rabbits against huSorCS2 aa 1138-1159, coupled to KLH, 1:300; or extracellular domain directed: R\&D Systems, 1:100), CD140b (PDGFR- $\beta$, eBioscience, 1:200), IB4 (preconjugated to biotin, Vector Laboratories, 1:300), activated caspase-3 (Cell Signaling Technology, 1:200), tyrosine hydroxylase (Millipore, 1:150), CD31 (BD, 1:100), CD41 (BD, 1:100), fibrin(ogen) (FITCconjugated, Dako, 1:250), CD68 (TRITC-conjugated, Serotec, 1:100), CD45 (BD, 1:200), and Gr1 (BD, 1:200). Biotinylated secondary antibodies were conjugated to $\mathrm{ABC}$ reagent and detected using the VIP Peroxidase Substrate kit (Vector Laboratories). Immunofluorescence was performed as described, except without peroxide treatment. Alexa Fluor-conjugated secondary antibodies (Invitrogen) were used to detect primary antibodies. Light microscopy was performed on a microscope (Olympus) and a QImaging Retiga EXi camera and a BX50 microscope (Olympus) and MicroFire digital camera (Optronics). Immunofluorescent microscopy was performed using either a Observer.Z1 (Carl Zeiss) or an Eclipse 80i (Nikon). Digital images were acquired with an AxioCam MRm or AxioCam MRc camera and AxioVision 4.8 software or with a QImaging Retiga1300i camera and Q Capture or Elements software (Nikon).

Transthoracic echocardiography. An Accuson Sequoia clinical ultrasound equipped with a $14 \mathrm{~Hz}$ probe was used for this study. Each mouse was anesthetized using Avertin, allowed to recover baseline heart rate for at least $20 \mathrm{~min}$ on a warming pad set on low temperature, and depilated before performing echocardiography. The probe head, whose range was extended using a $1-\mathrm{cm}$ gel offset, was applied to a layer of ultrasound gel, and the midline of the heart was detected by the visualization of the papillary muscles in the left ventricle in cross section. Once the midline was identified, the probe was swept up and down the caudal-rostral axis of the heart to ensure observation at the widest part of the left ventricle, and then the probe was stabilized for $1 \mathrm{~min}$ of recording to VHS tape. A printout of the M mode was made, and diastolic and systolic left ventricular posterior wall thickness was measured. Calculation of the fractional shortening was done using the following formula: $\%$ fractional shortening $=[($ left ventricular end diastolic dimension - left ventricular end systolic diastolic dimension)/left ventricular end diastolic dimension] $\times 100$. All statistical analyses between groups were performed using a Student's $t$ test.

I-R surgery. Anesthesia was induced using $4 \%$ isoflurane inhalation and maintained with $2 \%$ isoflurane. Mice were then intubated and mechanically ventilated. Core body temperature was monitored with a rectal probe and maintained at $37^{\circ} \mathrm{C}$ and electrocardiogram was monitored throughout the surgery using a lead II configuration and PowerLab data acquisition system. A left thoractomy was performed in the fourth intercostal space and the pericardium was opened. The left anterior descending coronary artery was 
reversibly ligated with an $8-0$ suture for $45 \mathrm{~min}$ and then reperfused by release of the ligature. Occlusion was confirmed with ST segment elevation on the electrocardiogram, regional cyanosis, and wall motion abnormalities. Reperfusion was confirmed by return of color to the myocardium distal to the ligation and disappearance of ST elevation. The suture remained within the wound for identification of the ligature site, and the chest and skin were closed in layers. After surgery, animals were returned to individual cages and given regular food and water for $24 \mathrm{~h}$ or $3 \mathrm{~d}$ before euthanasia and tissue harvest. $0.1 \mathrm{mg} / \mathrm{kg}$ Buprenex was administered as needed to ensure that the animals were comfortable after surgery. All surgical procedures were performed under aseptic conditions.

Infarct/area at risk analysis. $10 \mathrm{~d}$ after the onset of reperfusion, the mice were anesthetized with $4 \%$ isoflurane. Once unconscious, the mice were intubated and mechanically ventilated and anesthesia was maintained with $2 \%$ inhaled isoflurane. The chest cavity was then reopened and the left anterior descending coronary artery was reoccluded using the same suture from the I-R procedure. Evans blue dye $(1 \mathrm{ml}$ of $1.5 \%$ [wt/vol] solution made with $0.9 \% \mathrm{NaCl}$ ) was infused through a polyethylene tube (PE10) in the right jugular vein to delineate the area at risk. The heart was then excised for infarct size analysis and cut into transverse sections $1 \mathrm{~mm}$ thick using a cutting block. Both sides of all slices were photographed for measurement of area at risk (ImageJ) The slices were then placed in 10\% neutral buffered formalin and fixed overnight at $4{ }^{\circ} \mathrm{C}$. The slices were then thoroughly washed with PBS and cryoprotected with $30 \%$ sucrose before embedding in OCT:30\% sucrose (1:1; Sakura). Masson's trichrome demonstration of collagen deposition was performed according to the manufacturer's instructions (PolyScientific R\&D Corp.) on cryosections from each of the $1 \mathrm{~mm}$ sections to identify the infarcted area. Sections stained by Masson's trichrome were photographed using a microscope (Olympus) with a $4 \times$ objective and a QImaging Retiga EXi camera. Composite images of the entire section were made using Photoshop.Total area, area at risk, and infarct areas for each slice were traced (ImageJ), and the area of myocardium at risk and infarcted myocardium were calculated from the measured areas. Infarct size was normalized as a fraction of the area at risk.

Electron microscopy. All reagents were purchased from Electron Microscopy Sciences. Hearts were dissected from mice, rinsed well in cold PBS, and immersed in modified Karnovsky's fixative (2.5\% glutaraldehyde, $4 \%$ paraformaldehyde, and $0.02 \%$ picric acid in $0.1 \mathrm{M}$ sodium cacodylate buffer, $\mathrm{pH} 7.3$ ) overnight. $1-\mathrm{mm}^{3}$ blocks were post-fixed in $1 \%$ osmium tetroxide $/ 1.5 \%$ potassium-ferricyanide, stained with $1.5 \%$ uranyl acetate, and dehydrated through a graded ethanol series. After embedding in Spurr's resin, sections were cut at 55-60 nm thickness using a diamond knife (Diatome) on an ultramicrotome (Ultracut S; Leica). Sections were contrasted with lead citrate and viewed on a JEM 100 CX-II electron microscope (JEOL) operated at $80 \mathrm{kV}$. Images were recorded on 4489 Electron Image film (Kodak) and then digitized at 900 dpi for publication.

Estimation of pericyte process length. Hearts from 1-mo-old NG2DsRedBAC; proNgf- $\mathrm{HA} /^{+}$mice and NG2DsRedBAC; $\mathrm{Ng}^{+/+}$littermates were sectioned at $30 \mu \mathrm{m}$ thickness and cover slipped. The sections were numbered blindly before quantitative analysis. To be selected for analysis, DsRed labeled pericytes had to meet the following characteristics: have a single cell body having primary processes growing out from the cell body and relatively isolated from neighboring pericytes; be positioned in the subepicardial layer of the heart, running in a longitudinal direction; and have intact processes with consistent NG2DsRed labeling. 20 pericytes from two sections from each animal were traced at $40 \times$ using NeuroLeucida software. Total process length was determined using NeuroExplorer software.

Online supplemental material. Table S1 describes patient information. Online supplemental material is available at http://www.jem.org/cgi/ content/full/jem.20111749/DC1.

We thank Chingwen Yang and Roger Pearse for help in design of targeting constructs, Katherine Hajjar for use of clinical ultrasound equipment and a Nikon microscope, and Paraskevi Giannakakou for use of the confocal microscope. We thank Francis Lee, Zheyu Chen, Eric Wilkens, Teresa Milner, Rosemary Kraemer, K.M. Faisal Khan, Degiang

Jing, and members of the Hempstead laboratory for valuable discussions. This work was supported by National Institutes of Health (HLO46403 and

NS030687) to B.L. Hempstead and by NIH HL093056 to B.A. Habecker. There are no conflicts of interest.

Author contributions: C.-J. Siao created the knockin mouse model, designed and performed experiments, and co-wrote the paper. C.U. Lorentz designed and performed experiments and co-wrote the paper. T. Marinic, J. Carter, K. McGrath, V. Padow, D.C. Parrish, and L. Cohen-Gould performed experiments. W. Mark, B.A. Habecker, L. Tessarollo, A. Nykjaer, D.J. Falcone, and L.H. Ellenson provided integral services or reagents and contributed to design of experiments. B.L. Hempstead designed and co-wrote the paper.

Submitted: 19 August 2011

Accepted: 14 September 2012

\section{REFERENCES}

Allt, G., and J.G. Lawrenson. 2001. Pericytes: cell biology and pathology. Cells Tissues Organs (Print). 169:1-11. http://dx.doi.org/10.1159/ 000047855

Armulik, A., A. Abramsson, and C. Betsholtz. 2005. Endothelial/pericyte interactions. Circ. Res. 97:512-523. http://dx.doi.org/10.1161/01.RES $.0000182903 .16652 . \mathrm{d} 7$

Bekkers, S.C., S.K. Yazdani, R. Virmani, and J. Waltenberger. 2010. Microvascular obstruction: underlying pathophysiology and clinical diagnosis. J. Am. Coll. Cardiol. 55:1649-1660. http://dx.doi.org/10.1016/ j.jacc.2009.12.037

Bjarnegård, M., M. Enge, J. Norlin, S. Gustafsdottir, S. Fredriksson, A. Abramsson, M. Takemoto, E. Gustafsson, R. Fässler, and C. Betsholtz. 2004. Endothelium-specific ablation of PDGFB leads to pericyte loss and glomerular, cardiac and placental abnormalities. Development. 131:18471857. http://dx.doi.org/10.1242/dev.01080

Camilleri, J.P., M.O. Nlom, D. Joseph, J.B. Michel, D. Barres, and J. Mignot. 1983. Capillary perfusion patterns in reperfused ischemic subendocardial myocardium: experimental study using fluorescent dextran. Exp. Mol. Pathol. 39:89-99. http://dx.doi.org/10.1016/0014-4800(83)90043-6

Crowley, C.S., S.D. Spencer, M.C. Nishimura, K.S. Chen, S. Pitts-Meek, M.P. Armanini, L.H. Ling, S.B. McMahon, D.L. Shelton, A.D. Levinson, and H.S. Phillips. 1994. Mice lacking nerve growth factor display perinatal loss of sensory and sympathetic neurons yet develop basal forebrain cholinergic neurons. Cell. 76:1001-1011. http://dx.doi.org/ 10.1016/0092-8674(94)90378-6

Deinhardt, K., T. Kim, D.S. Spellman, R.E. Mains, B.A. Eipper, T.A. Neubert, M.V. Chao, and B.L. Hempstead. 2011. Neuronal growth cone retraction relies on proneurotrophin receptor signaling through Rac. Sci. Signal. 4:ra82. http://dx.doi.org/10.1126/scisignal.2002060

Donovan, M.J., R.C. Miranda, R. Kraemer, T.A. McCaffrey, L. Tessarollo, D. Mahadeo, S. Sharif, D.R. Kaplan, P. Tsoulfas, L. Parada, et al. 1995. Neurotrophin and neurotrophin receptors in vascular smooth muscle cells. Regulation of expression in response to injury. Am. J. Pathol. 147: 309-324.

Dumont, D.J., G. Gradwohl, G.H. Fong, M.C. Puri, M. Gertsenstein, A. Auerbach, and M.L. Breitman. 1994. Dominant-negative and targeted null mutations in the endothelial receptor tyrosine kinase, tek, reveal a critical role in vasculogenesis of the embryo. Genes Dev. 8:1897-1909. http://dx.doi.org/10.1101/gad.8.16.1897

El-Bizri, N., L. Wang, S.L. Merklinger, C. Guignabert, T. Desai, T. Urashima, A.Y. Sheikh, R.H. Knutsen, R.P. Mecham, Y. Mishina, and M. Rabinovitch. 2008. Smooth muscle protein 22alpha-mediated patchy deletion of Bmpr1a impairs cardiac contractility but protects against pulmonary vascular remodeling. Circ. Res. 102:380-388. http:// dx.doi.org/10.1161/CIRCRESAHA.107.161059

Eltzschig, H.K., and C.D. Collard. 2004. Vascular ischaemia and reperfusion injury. Br. Med. Bull. 70:71-86. http://dx.doi.org/10.1093/bmb/ldh025

Fanburg-Smith, J.C., and M. Miettinen. 2001. Low-affinity nerve growth factor receptor $(\mathrm{p} 75)$ in dermatofibrosarcoma protuberans and other 
nonneural tumors: a study of 1,150 tumors and fetal and adult normal tissues. Hum. Pathol. 32:976-983. http://dx.doi.org/10.1053/hupa .2001 .27602

Gaengel, K., G. Genové, A. Armulik, and C. Betsholtz. 2009. Endothelialmural cell signaling in vascular development and angiogenesis. Arterioscler. Thromb. Vasc. Biol. 29:630-638. http://dx.doi.org/10.1161/ ATVBAHA.107.161521

Gentry, J.J., P.A. Barker, and B.D. Carter. 2004. The p75 neurotrophin receptor: multiple interactors and numerous functions. Prog. Brain Res. 146:25-39. http://dx.doi.org/10.1016/S0079-6123(03)46002-0

Glebova, N.O., and D.D. Ginty. 2005. Growth and survival signals controlling sympathetic nervous system development. Annu. Rev. Neurosci. 28:191222. http://dx.doi.org/10.1146/annurev.neuro.28.061604.135659

Habecker, B.A., P. Bilimoria, C. Linick, K. Gritman, C.U. Lorentz, W Woodward, and S.J. Birren. 2008. Regulation of cardiac innervation and function via the p75 neurotrophin receptor. Auton. Neurosci. 140:40-48. http://dx.doi.org/10.1016/j.autneu.2008.03.002

Harrington, A.W., B. Leiner, C. Blechschmitt, J.C. Arevalo, R. Lee, K. Mörl, M. Meyer, B.L. Hempstead, S.O. Yoon, and K.M. Giehl. 2004. Secreted proNGF is a pathophysiological death-inducing ligand after adult CNS injury. Proc. Natl. Acad. Sci. USA. 101:6226-6230. http:// dx.doi.org/10.1073/pnas.0305755101

Hasan, W., A. Jama, T. Donohue, G. Wernli, G. Onyszchuk, B. Al-Hafez, M. Bilgen, and P.G. Smith. 2006. Sympathetic hyperinnervation and inflammatory cell NGF synthesis following myocardial infarction in rats. Brain Res. 1124:142-154. http://dx.doi.org/10.1016/ j.brainres.2006.09.054

Hellström, M., M. Kalén, P. Lindahl, A. Abramsson, and C. Betsholtz. 1999. Role of PDGF-B and PDGFR-beta in recruitment of vascular smooth muscle cells and pericytes during embryonic blood vessel formation in the mouse. Development. 126:3047-3055.

Hempstead, B.L. 2009. Commentary: Regulating proNGF action: multiple targets for therapeutic intervention. Neurotox. Res. 16:255-260. http:// dx.doi.org/10.1007/s12640-009-9054-9

Heymach, J.V. Jr., and E.M. Shooter. 1995. The biosynthesis of neurotrophin heterodimers by transfected mammalian cells. J. Biol. Chem. 270:12297-12304.

Hiltunen, J.O., A. Laurikainen, A. Väkevä, S. Meri, and M. Saarma. 2001. Nerve growth factor and brain-derived neurotrophic factor mRNAs are regulated in distinct cell populations of rat heart after ischaemia and reperfusion. J. Pathol. 194:247-253. http://dx.doi.org/10 $.1002 /$ path. 878

Jansen, P., K. Giehl, J.R. Nyengaard, K. Teng, O. Lioubinski, S.S. Sjoegaard, T. Breiderhoff, M. Gotthardt, F. Lin, A. Eilers, et al. 2007. Roles for the pro-neurotrophin receptor sortilin in neuronal development, aging and brain injury. Nat. Neurosci. 10:1449-1457. http://dx.doi.org/ $10.1038 / \mathrm{nn} 2000$

Kapadia, S.R., H. Oral, J. Lee, M. Nakano, G.E. Taffet, and D.L. Mann. 1997. Hemodynamic regulation of tumor necrosis factor-alpha gene and protein expression in adult feline myocardium. Circ. Res. 81:187-195. http://dx.doi.org/10.1161/01.RES.81.2.187

Kim, H., Q. Li, B.L. Hempstead, and J.A. Madri. 2004. Paracrine and autocrine functions of brain-derived neurotrophic factor (BDNF) and nerve growth factor (NGF) in brain-derived endothelial cells. J. Biol. Chem. 279:33538-33546. http://dx.doi.org/10.1074/jbc.M404115200

Kloner, R.A.C.E.G.A.N.O.T.E., C.E. Ganote, and R.B. Jennings. 1974. The "no-reflow" phenomenon after temporary coronary occlusion in the dog. J. Clin. Invest. 54:1496-1508. http://dx.doi.org/10.1172/JCI107898

Koshimizu, H., K. Kiyosue, T. Hara, S. Hazama, S. Suzuki, K. Uegaki, G. Nagappan, E. Zaitsev, T. Hirokawa, Y. Tatsu, et al. 2009. Multiple functions of precursor BDNF to CNS neurons: negative regulation of neurite growth, spine formation and cell survival. Mol. Brain. 2:27. http://dx.doi.org/10.1186/1756-6606-2-27

Kraemer, R. 2002. Reduced apoptosis and increased lesion development in the flow-restricted carotid artery of p75(NTR)-null mutant mice. Circ. Res. 91:494-500. http://dx.doi.org/10.1161/01.RES.0000035245.83233.2A

Larsson, J., M.J. Goumans, L.J. Sjöstrand, M.A. van Rooijen, D. Ward, P. Levéen, X. Xu, P. ten Dijke, C.L. Mummery, and S. Karlsson. 2001. Abnormal angiogenesis but intact hematopoietic potential in TGF-beta type
I receptor-deficient mice. EMBO J. 20:1663-1673. http://dx.doi.org/ 10.1093/emboj/20.7.1663

Lebrin, F., S. Srun, K. Raymond, S. Martin, S. van den Brink, C. Freitas, C. Bréant, T. Mathivet, B. Larrivée, J.L. Thomas, et al. 2010. Thalidomide stimulates vessel maturation and reduces epistaxis in individuals with hereditary hemorrhagic telangiectasia. Nat. Med. 16:420-428. http:// dx.doi.org/10.1038/nm.2131

Lee, R., P. Kermani, K.K. Teng, and B.L. Hempstead. 2001. Regulation of cell survival by secreted proneurotrophins. Science. 294:1945-1948. http://dx.doi.org/10.1126/science.1065057

Lindahl, P., B.R. Johansson, P. Levéen, and C. Betsholtz. 1997. Pericyte loss and microaneurysm formation in PDGF-B-deficient mice. Science. 277:242-245. http://dx.doi.org/10.1126/science.277.5323.242

Lommatzsch, M., D. Quarcoo, O. Schulte-Herbrüggen, H. Weber, J.C. Virchow, H. Renz, and A. Braun. 2005. Neurotrophins in murine viscera: a dynamic pattern from birth to adulthood. Int. J. Dev. Neurosci. 23:495-500. http://dx.doi.org/10.1016/j.ijdevneu.2005.05.009

Lorentz, C.U., W.R. Woodward, K. Tharp, and B.A. Habecker. 2011. Altered norepinephrine content and ventricular function in p75NTR-/mice after myocardial infarction. Auton. Neurosci. 164:13-19. http:// dx.doi.org/10.1016/j.autneu.2011.05.002

Luther, J.A., and S.J. Birren. 2006. Nerve growth factor decreases potassium currents and alters repetitive firing in rat sympathetic neurons. $J$. Neurophysiol. 96:946-958. http://dx.doi.org/10.1152/jn.01078.2005

Mann, D.L. 2003. Stress-activated cytokines and the heart: from adaptation to maladaptation. Annu. Rev. Physiol. 65:81-101. http://dx.doi.org/ 10.1146/annurev.physiol.65.092101.142249

Meloni, M., A. Caporali, G. Graiani, C. Lagrasta, R. Katare, S. Van Linthout, F. Spillmann, I. Campesi, P. Madeddu, F. Quaini, and C. Emanueli. 2010. Nerve growth factor promotes cardiac repair following myocardial infarction. Circ. Res. 106:1275-1284. http://dx.doi.org/10 .1161/CIRCRESAHA.109.210088

Nian, M., P. Lee, N. Khaper, and P. Liu. 2004. Inflammatory cytokines and postmyocardial infarction remodeling. Circ. Res. 94:1543-1553. http:// dx.doi.org/10.1161/01.RES.0000130526.20854.fa

Nykjaer, A., R. Lee, K.K. Teng, P. Jansen, P. Madsen, M.S. Nielsen, C. Jacobsen, M. Kliemannel, E. Schwarz, T.E. Willnow, et al. 2004. Sortilin is essential for proNGF-induced neuronal cell death. Nature. 427:843-848. http://dx.doi.org/10.1038/nature02319

Nykjaer, A., T.E. Willnow, and C.M. Petersen. 2005. p75NTR-live or let die. Curr. Opin. Neurobiol. 15:49-57. http://dx.doi.org/10.1016/ j.conb.2005.01.004

Oh, S.P., T. Seki, K.A. Goss, T. Imamura, Y. Yi, P.K. Donahoe, L. Li, K. Miyazono, P. ten Dijke, S. Kim, and E. Li. 2000. Activin receptor-like kinase 1 modulates transforming growth factor-beta 1 signaling in the regulation of angiogenesis. Proc. Natl. Acad. Sci. USA. 97:2626-2631. http://dx.doi.org/10.1073/pnas.97.6.2626

Osoegawa, K., M. Tateno, P.Y. Woon, E. Frengen, A.G. Mammoser, J.J. Catanese, Y. Hayashizaki, and P.J. de Jong. 2000. Bacterial artificial chromosome libraries for mouse sequencing and functional analysis. Genome Res. 10:116-128.

Panés, J., M. Perry, and D.N. Granger. 1999. Leukocyte-endothelial cell adhesion: avenues for therapeutic intervention. Br. J. Pharmacol. 126:537550. http://dx.doi.org/10.1038/sj.bjp.0702328

Pavlovic, S., B. Du, K. Sakamoto, K.M. Khan, C. Natarajan, R.M. Breyer, A.J. Dannenberg, and D.J. Falcone. 2006. Targeting prostaglandin E2 receptors as an alternative strategy to block cyclooxygenase-2-dependent extracellular matrix-induced matrix metalloproteinase- 9 expression by macrophages. J. Biol. Chem. 281:3321-3328. http://dx.doi.org/10 $.1074 /$ jbc.M506846200

Pedraza, C.E., P. Podlesniy, N. Vidal, J.C. Arévalo, R. Lee, B.L. Hempstead, I. Ferrer, M. Iglesias, and C. Espinet. 2005. Pro-NGF isolated from the human brain affected by Alzheimer's disease induces neuronal apoptosis mediated by p75NTR. Am. J. Pathol. 166:533-543. http://dx.doi .org/10.1016/S0002-9440(10)62275-4

Reichardt, L.F. 2006. Neurotrophin-regulated signalling pathways. Philos. Trans. R. Soc. Lond. B Biol. Sci. 361:1545-1564. http://dx.doi.org/ $10.1098 / \mathrm{rstb} .2006 .1894$ 
Roura, S., and A. Bayes-Genis. 2009. Vascular dysfunction in idiopathic dilated cardiomyopathy. Nat Rev Cardiol. 6:590-598. http://dx.doi.org/ 10.1038/nrcardio.2009.130

Sachs, B.D., G.S. Baillie, J.R. McCall, M.A. Passino, C. Schachtrup, D.A Wallace, A.J. Dunlop, K.F. MacKenzie, E. Klussmann, M.J. Lynch, et al.2007.p75 neurotrophin receptor regulates tissue fibrosis through inhibition of plasminogen activation via a PDE4/cAMP/PKA pathway. J. Cell Biol. 177:1119-1132. http://dx.doi.org/10.1083/jcb .200701040

Sakai, K., and J. Miyazaki. 1997. A transgenic mouse line that retains Cre recombinase activity in mature oocytes irrespective of the cre transgene transmission. Biochem. Biophys. Res. Commun. 237:318-324. http://dx .doi.org/10.1006/bbrc.1997.7111

Sato, T.N., Y. Tozawa, U. Deutsch, K. Wolburg-Buchholz, Y. Fujiwara, M. Gendron-Maguire, T. Gridley, H. Wolburg, W. Risau, and Y. Qin. 1995. Distinct roles of the receptor tyrosine kinases Tie-1 and Tie-2 in blood vessel formation. Nature. 376:70-74. http://dx.doi.org/10 $.1038 / 376070 \mathrm{a} 0$

Shepro, D., and N.M. Morel. 1993. Pericyte physiology. FASEB J. 7:1031-1038.

Springer, T.A. 1994. Traffic signals for lymphocyte recirculation and leukocyte emigration: the multistep paradigm. Cell. 76:301-314. http:// dx.doi.org/10.1016/0092-8674(94)90337-9

Suri, C., P.F. Jones, S. Patan, S. Bartunkova, P.C. Maisonpierre, S. Davis, T.N. Sato, and G.D. Yancopoulos. 1996. Requisite role of angiopoietin1, a ligand for the TIE2 receptor, during embryonic angiogenesis. Cell. 87:1171-1180. http://dx.doi.org/10.1016/S0092-8674(00)81813-9

Teng, K.K., S. Felice, T. Kim, and B.L. Hempstead. 2010. Understanding proneurotrophin actions: Recent advances and challenges. Dev. Neurobiol. 70:350-359.
Volosin, M., W. Song, R.D. Almeida, D.R. Kaplan, B.L. Hempstead, and W.J. Friedman. 2006. Interaction of survival and death signaling in basal forebrain neurons: roles of neurotrophins and proneurotrophins. J. Neurosi. 26:7756-7766. http://dx.doi.org/10.1523/JNEUROSCI.1560-06.2006

Volosin, M., C. Trotter, A. Cragnolini, R.S. Kenchappa, M. Light, B.L. Hempstead, B.D. Carter, and W.J. Friedman. 2008. Induction of proneurotrophins and activation of p75NTR-mediated apoptosis via neurotrophin receptor-interacting factor in hippocampal neurons after seizures. J. Neurosci. 28:9870-9879. http://dx.doi.org/10.1523/ JNEUROSCI.2841-08.2008

Walshe, T.E., M. Saint-Geniez, A.S.R. Maharaj, E. Sekiyama, A.E. Maldonado, and P.A. D'Amore. 2009. TGF-beta is required for vascular barrier function, endothelial survival and homeostasis of the adult microvasculature. PLoS ONE. 4:e5149. http://dx.doi.org/10.1371/ journal.pone.0005149

Wang, S., P. Bray, T. McCaffrey, K. March, B.L. Hempstead, and R. Kraemer. 2000. p75(NTR) mediates neurotrophin-induced apoptosis of vascular smooth muscle cells. Am. J. Pathol. 157:1247-1258. http:// dx.doi.org/10.1016/S0002-9440(10)64640-8

Willnow, T.E., C.M. Petersen, and A. Nykjaer. 2008. VPS10P-domain receptors - regulators of neuronal viability and function. Nat. Rev. Neurosci. 9:899-909. http://dx.doi.org/10.1038/nrn2516

Yang, F., H.S. Je, Y. Ji, G. Nagappan, B. Hempstead, and B. Lu. 2009. Pro-BDNF-induced synaptic depression and retraction at developing neuromuscular synapses. J. Cell Biol. 185:727-741. http://dx.doi .org/10.1083/jcb.200811147

Zhu, X., R.A. Hill, and A. Nishiyama. 2008. NG2 cells generate oligodendrocytes and gray matter astrocytes in the spinal cord. Neuron Glia Biol. 4:19-26. http://dx.doi.org/10.1017/S1740925X09000015 